\title{
Inflation Expectations, Learning, and Supermarket Prices: Evidence from Survey Experiments
}

\author{
By Alberto Cavallo, Guillermo Cruces, and Ricardo Perez-Truglia
}

\begin{abstract}
Information frictions play a central role in the formation of household inflation expectations, but there is no consensus about their origins. We address this question with novel evidence from survey experiments. We document two main findings. First, individuals in low inflation contexts have significantly weaker priors about the inflation rate. This finding suggests that rational inattention may be an important source of information frictions. Second, cognitive limitations also appear to be a source of information frictions: even when information about inflation statistics is available, individuals still place a significant weight on inaccurate sources of information, such as their memories of the price changes of the supermarket products they purchase. We discuss the implications of these findings for macroeconomic models and policymaking. (JEL D83, D84, E31, L11, L81, O11)
\end{abstract}

E xpectations about macroeconomic variables play an essential role in economic theory and policymaking. Consumer inflation expectations, in particular, are key to understanding household consumption and investment decisions and ultimately the impact of monetary policies. Although central banks seek to influence expectations, there is no consensus in the empirical literature on how household inflation expectations are formed or influenced (see Bernanke 2007; Bachmann, Berg, and Sims 2015; and Coibion and Gorodnichenko 2015).

Consumer surveys indicate that household inflation expectations tend to be much more heterogeneous than those of professional forecasters (Ranyard et al. 2008, Armantier et al. 2013). The literature offers two main explanations for this difference. Some authors attribute it to rational inattention, according to which individuals only partly incorporate information on topics such as inflation, because acquiring that information is costly (relative to the potential gains from using that

*Cavallo: Sloan School of Management, Massachusetts Institute of Technology, 100 Main Street, Office E62-512, Cambridge, MA 02142 (email: acavallo@mit.edu); Cruces: Universidad Nacional de La Plata, CEDLASFCE, Calle 6, La Plata, Argentina (email: gcruces@cedlas.org); Perez-Truglia: Anderson School of Management, University of California, Los Angeles, Office C515, 110 Westwood Plaza, Los Angeles, CA 90403 (email: ricardo. truglia@anderson.ucla.edu). We would like to thank Robert Barro, Raj Chetty, and David Laibson for their valuable input at the early stages of the project. Thanks to two anonymous referees for their excellent feedback. Julian Amendolaggine and Nicolas Badaracco did excellent work as research assistants. We would also like to thank Tomas Pessacq and Carolina Yellati for their collaboration in conducting the experiments, and MIT Sloan and CEDLAS-UNLP for their funding. This project was reviewed and approved by the Committee on the Use of Humans as Experimental Subjects at MIT.

Go to https://doi.org/10.1257/mac.20150147 to visit the article page for additional materials and author disclosure statement(s) or to comment in the online discussion forum. 
information). This explanation is particularly convincing in contexts of low inflation, like the United States, where the potential financial cost of ignoring inflation is negligible for most households. Other authors argue that, in forming inflation expectations, individuals use information derived from their personal experiences as consumers, which can be both diverse and inaccurate (Bruine de Bruin, van der Klaauw, and Topa 2011; Malmendier and Nagel 2016; and Madeira and Zafar 2015). The evidence on information frictions cannot distinguish between different sources of frictions. These distinctions can be important, however, to the extent that different sources can lead to very different policy prescriptions.

We present evidence from a series of experiments specifically designed to test the hypotheses of rational inattention and personal consumer experience. In a series of online and offline surveys, we randomly provided subjects with information related to past inflation. We provided information from different sources, such as inflation statistics and tables with historical prices of specific supermarket products. We then measured the effects of this information on the subjects' inflation expectations. With the help of a Bayesian learning model, we estimated how much weight subjects assigned to a given piece of information (e.g., an inflation statistic), relative to their prior beliefs about inflation.

The first goal of this paper is to provide a sharp test of the rational inattention model. To do so, we conducted survey experiments in two contexts: low inflation (i.e., the United States, where average annual inflation rate was 1.8 percent in the five years prior to our study) and high inflation (i.e., Argentina, where average annual inflation rate was around 22.5 percent over the same period) 1 According to the rational inattention model, individuals in a high inflation context should have strong priors about inflation because the financial cost of misperceiving inflation is high. They should thus seek high quality information and do so more often (Mankiw, Reis, and Wolfers 2004; Carroll 2003). Consistent with this hypothesis, we find that individuals in the low inflation context had weaker priors about the inflation rate compared to those in the high inflation context. For example, when provided with information about inflation statistics or prices of specific supermarket products, individuals in the low inflation context (United States) assigned a weight of just 15 percent to their prior beliefs, whereas individuals in the high inflation context (Argentina) assigned a weight of roughly 50 percent.

The second goal of this paper is to measure whether cognitive limitations are important sources of information frictions. To do so, we compared how individuals incorporated two types of information about inflation: inflation statistics and historical prices for a handful of randomly selected supermarket products, which served as a proxy for the type of information that individuals obtain from personal shopping experiences. $]$ Relative to the average price change from a random set of six products, inflation statistics were much more precisely estimated. We expected an economic professional to assign all weight to the statistics information and to

\footnotetext{
${ }^{1}$ We do not use official inflation statistics for Argentina because they were widely discredited. We use instead alternative indicators compiled by the private sector, which are well known and widely cited in the media.

${ }^{2}$ The data was scraped off of the websites of some of the largest supermarkets in the United States and Argentina as part of the Billion Prices Project at MIT.
} 
ignore the supermarket price information when given both pieces of information. Instead, when subjects were given these two types of information simultaneously, they implicitly assigned as much weight to supermarket prices as they did to inflation statistics. In other words, even when information about inflation statistics was readily available, individuals assigned significant value to less accurate sources of information.

Our experimental design tries to address a common criticism of survey experiments that, instead of inducing genuine learning, the information provided in the experiment elicits spurious reactions. For instance, if an individual is told that the annual inflation rate was 2 percent and is later asked about inflation expectations, that individual may report an inflation expectation that is closer to 2 percent for spurious reasons, such as to please the interviewer (Goffman 1963), to avoid being perceived as ignorant, or because of unconscious numerical anchoring (Tversky and Kahneman 1974) Indeed, to illustrate how easy it is to manipulate the subjects' responses, we show that providing explicitly fictitious information on price changes had a statistically and economically significant effect on inflation expectations.

Our experimental design employed two methods for separating reactions based on genuine learning from those based on spurious learning. The first method exploits the condition that, if the reaction to the information was spurious, then the experimental effects should not persist for months after the information provision. The second method exploits the condition that, if the reaction to the information was spurious, then we should not observe effects on expectations about other nominal variables that are intrinsically related to the inflation rate, such as the nominal interest rate. Results from these two methods suggest that concerns about spurious learning are justified and must be taken seriously, because half of the reactions to our informational treatments are spurious. Nevertheless, our main results remain unchanged after we control for spurious learning.

Another concern is that subjects may react to the information on supermarket prices that we provide because they perceive it as accurate but do not trust their own memories about supermarket prices. Also, using price memories to form inflation expectations is misleading only insofar as those memories are inaccurate. Addressing these remaining questions requires data that would be difficult to collect in an online survey. Thus, we conducted a unique consumer-intercept survey experiment to address these questions. Among other things, we recorded consumers' purchases by scanning participants' supermarket receipts, which we linked to data on the actual historical prices of those same products at the same store. We also asked respondents to recall historical prices for a random selection of the items that they had just purchased, which allowed us to generate exogenous variations in the salience of the subjects' own price memories. The evidence from this experiment suggests that individuals do use their own memories about supermarket prices when

\footnotetext{
${ }^{3}$ This result is also consistent with survey evidence presented by Bruine de Bruin, van der Klaauw, and Topa (2011), who show that, when asked about the inflation rate, most individuals report that they try to recall the prices of specific products.

${ }^{4}$ This criticism is common to survey experiments in general, not particularly to our application in the area of inflation expectations. See Rosenthal (1966) for a discussion of effects of this type in behavioral research, and Zizzo (2010) for a recent application to experimental economics.
} 
forming inflation expectations and that those memories are largely inaccurate and thus induce large errors in expectations.

Our findings provide useful lessons for macroeconomic theory. The idea that monetary policy can have real effects due to information frictions dates back to Phelps (1969) and Lucas (1972). More recently, Mankiw and Reis (2002) show how the New Keynesian Phillips curve can be the product of sticky information. The policy prescriptions depend on how we model information frictions, but there is no consensus about which model is best (Coibion and Gorodnichenko 2012). Our evidence suggests that, in addition to rational inattention models, the literature should incorporate cognitive limitations.

Our findings are also related to recent debates about central bank transparency. Some authors argue that information disclosure can enhance welfare (Hellwig 2005), and others argue that it can reduce welfare (Morris and Shin 2002). Our findings suggest that, even when the statistics are publicly and readily available, households instead use less accurate private information. This implies that, in addition to the dissemination of aggregate statistics, central banks may have an additional policy margin in terms of communicating how objective, precise, and representative these statistics are. For example, the European Central Bank and the French statistical agency have made notable efforts to create online tools to convey this information, including the way it is collected and processed, in a user friendly way. 9 Central banks interested in affecting individual expectations could also disseminate more relatable information, such as the price changes of specific products. All these efforts may help central banks increase the speed with which individuals react to monetary policy and help households make better financial decisions (Armantier et al. 2013) 7

Our paper belongs to a literature that tries to understand the formation of household inflation expectations. Some studies have measured the role of inflation statistics, exploiting media coverage of statistics (Lamla and Lein 2008, Badarinza and Buchmann 2009, and Dräger 2011), the publication of official statistics (Carrillo and Emran 2012), and information provision experiments (Roos and Schmidt 2012, Armantier et al. 2016). Other studies have looked at the role of personal experiences. For instance, evidence suggets that individuals use information from their own price memories (Bates and Gabor 1986; Bruine de Bruin, van der Klaauw, and Topa 2011; and Coibion and Gorodnichenko 2015) and that individuals place excessive weight on information about past inflation levels that they personally experienced (Malmendier and Nagel 2016).

Thus far, the literature has been unable to distinguish between different sources of information friction (Ranyard et al. 2008). Some evidence shows that individuals fail to incorporate all available information. Some authors interpret this as evidence of

\footnotetext{
${ }^{5}$ The literature on memory in psychology and behavioral economics provides useful models for these cognitive limitations. See, for example, Mullainathan (2002) and Gennaioli and Shleifer (2010).

${ }^{6}$ See http://www.ecb.europa.eu/ecb/educational/hicp/html/index.en.html and http://www.insee.fr/en/ indicateurs/indic_cons/sip/sip.htm, respectively.

${ }^{7}$ The distribution of the bias is relevant as well. If poorer and less educated consumers had larger biases, as observed in many datasets, then correcting their biases may reduce these consumers' relative disadvantages.
} 
rational inattention (e.g., Mankiw, Reis, and Wolfers 2004), 8 while other authors interpret this as evidence of irrational inattention (e.g., Bruine de Bruin, van der Klaauw, and Topa 2011; Malmendier and Nagel 2016). Our contribution to this literature is to design experiments that disentangle these two sources of information frictions, rational inattention and irrational learning, by exploiting variations in stakes (i.e., contexts of high versus low inflation) and sources of information (i.e., inflation statistics versus supermarket prices).

Methodologically, our paper is related to a recent subset of the literature that employs survey experiments to investigate household inflation expectations. For example, studies by Roos and Schmidt (2012) and Armantier et al. (2016) examine how individuals react to information about US inflation statistics by adjusting their reported inflation perceptions. Bruine de Bruin, van der Klaauw, and Topa (2011) show that subjects who are asked to think about products with extreme price changes tend to report high inflation expectations. We contribute to this literature by extending these methods to answer novel questions about the sources of information frictions. Additionally, we make several methodological contributions, such as disentangling genuine from spurious learning and combining survey with administrative data to study how individuals learn about supermarket prices.

The paper proceeds as follows. Section I describes the general experimental design. Section II presents evidence from a series of online experiments conducted in the United States and Argentina. Section III presents evidence from the consumer intercept survey experiment. Section IV concludes.

\section{Experimental Design}

\section{A. Structure of the Survey Experiments}

In this section, we describe the experimental framework for the empirical analysis in this paper. This framework builds upon several previous experimental studies (e.g., Bruine de Bruin, van der Klaauw, and Topa 2011; Roos and Schmidt 2012; and Armantier et al. 2016), and it introduces innovations aimed at testing new hypotheses and addressing the concern of spurious learning.

The basic structure of the survey experiments is as follows:

- Eliciting subjects' inflation perceptions (i.e., the perception of the annual inflation rate over the previous 12 months). This constitutes the individual's prior belief $\left(\pi_{i, t}^{0}\right.$ in the model in the following section).

- Providing the subject with information related to the inflation rate over the previous 12 months, which constitutes the signal $\left(\pi_{i, t}^{T}\right)$. In the case of the control group with no information provision, there is no signal. The different pieces of information provided to the subjects is described in the following subsection.

\footnotetext{
${ }^{8}$ For example, Demery and Duck (2007) argue that individuals may optimally decide to use solely information they receive as a byproduct of their economic activity, rather than complementing that information with official statistics.
} 
- Eliciting subjects' expectations about inflation (i.e., the expected annual inflation rate over the following 12 months, $\pi_{i, t+1}$ ) and other nominal variables (e.g., the nominal interest rate, $\left.i_{i, t+1}\right)$. These expectations may be elicited right after the information provision or several months later.

The main analysis consists of measuring how the information provided to individuals changes their expectations about the future. When eliciting inflation perceptions and expectations, we always refer to the general price level rather than to the prices of the goods purchased by the respondent. 9 We did not provide any incentives (e.g., prizes for guessing the right figures). However, as shown by Armantier et al. (2011), there is a significant correlation between incentivized and non-incentivized beliefs on inflation expectations.

\section{B. Treatment Arms}

After eliciting past inflation perceptions, subjects were randomly assigned to either a control group (with no information) or one of four treatment arms. This section describes these treatment arms.

The snapshots of the informational treatments and the survey questions are shown in the online questionnaire Appendix. Figure 1 shows the samples of the information treatments in the US online experiment 10 Our first treatment arm, shown in panel C of Figure 1, aimed to capture how individuals incorporate information from inflation statistics. This Statistics (1.5 percent) treatment consisted of a table with the most recent statistics about annual inflation at the time of the survey, and it was preceded by an explanation of what they were intended to measure (see the note accompanying Figure 1 for the exact wording). The average of the three statistics indicated an annual average inflation rate of 1.5 percent, which was also displayed on the table.

Our second treatment arm was designed to capture the degree to which individuals use the information related to their everyday experience when forming inflation expectations, even if that information is not as representative and precise as aggregate inflation statistics. The Products treatment arm, illustrated in panels A and B of Figure 1, presented respondents with a table containing the prices of six products at the time of the survey and one year earlier, as well as the price change (in percentage points) for each product and the average percentage price change for all products presented in the table, also for the period from August 1, 2012 to August 1, 2013. This table was preceded by an explanatory paragraph (see the note accompanying Figure 1 for the exact wording).

\footnotetext{
${ }^{9}$ Specifically, for the US online experiment, we asked participants the following two questions, taken directly from the University of Michigan's Survey of Consumers: "During the next 12 months, do you think that prices in general will go up, or go down, or stay where they are now?" with three options: "Go up," "Stay the same," and "Go down." We then asked, "By about what percentage do you expect prices to change, on average, during the next 12 months?" with an open numerical answer. For the Argentina online experiment, we opted to repeat the format of the question that had been asked in previous rounds of the opinion poll: "What do you think will be the annual inflation rate for the following 12 months?" (see the Appendix for exact wording in Spanish).

${ }^{10}$ Please find the corresponding figure for the Argentina online experiment in the online Appendix.
} 
Panel A. Products (-2\%)

\begin{tabular}{|c|c|c|c|}
\hline Product & $\begin{array}{c}\text { Price on } \\
\text { August 1, } 2012\end{array}$ & $\begin{array}{c}\text { Price on } \\
\text { August 1, } 2013\end{array}$ & $\begin{array}{l}\text { Price change } \\
\text { in } \%\end{array}$ \\
\hline Infant Formula (Enfamil Gentiease) & $\$ 18^{69}$ & $\$ 18^{69}$ & $0.0 \%$ \\
\hline Bread (Antio \& Sons Sub Rolts) & $\$ 3^{59}$ & $\$ 3^{50}$ & $0.0 \%$ \\
\hline Pasta Sauce (Barilla Marinara) & $\$ 2^{79}$ & $\$ 2^{30}$ & $0.4 \%$ \\
\hline Cereal (Cheerios Honey Nut) & $\$ 5^{20}$ & $\$ 4^{00}$ & $-5.7 \%$ \\
\hline Soda (Schweppes Ginger Ale) & $\$ 1^{79}$ & $\$ 1^{6 \gamma}$ & $-6.7 \%$ \\
\hline Body Wash (Dial Spring Water) & $\$ 6^{09}$ & $\$ 6^{\circ 9}$ & $0.0 \%$ \\
\hline \multicolumn{3}{|c|}{ Average change: } & $-2.0 \%$ \\
\hline
\end{tabular}

Panel C. Statistics (1.5\%)

\begin{tabular}{|c|c|}
\hline \multicolumn{1}{|c|}{ Official statistic } & $\begin{array}{c}\text { Average } \\
\text { annual change } \\
\text { in prices }\end{array}$ \\
\hline Consumer Price Index & $2.0 \%$ \\
\hline $\begin{array}{l}\text { Personal Consumption Expenditures } \\
\text { Price Index }\end{array}$ & $1.1 \%$ \\
\hline Gross Domestic Product Deflator $^{3}$ & $1.5 \%$ \\
\hline Average of the three statistics: & $1.5 \%$ \\
\hline
\end{tabular}

Panel B. Products $(2 \%)$

\begin{tabular}{|c|c|c|c|}
\hline Product & $\begin{array}{c}\text { Price on } \\
\text { August 1, } 2012 \\
\end{array}$ & $\begin{array}{c}\text { Price on } \\
\text { August 1, } 2013\end{array}$ & $\begin{array}{l}\text { Price change } \\
\text { in } \%\end{array}$ \\
\hline Infant Formula (Similac with iron) & $\$ 7^{29}$ & $\$ 7^{59}$ & $4.1 \%$ \\
\hline Bread (Pepperidge Farm Sliders) & $\$ 3^{00}$ & $\$ 2^{90}$ & $-0.3 \%$ \\
\hline Noodles (No Yolks) & $\$ 2^{79}$ & $\$ 2^{79}$ & $0.0 \%$ \\
\hline Cereal (Natures Path Envirokidz) & $\$ 4^{00}$ & $\$ 5^{20}$ & $8.0 \%$ \\
\hline Soda (Dr Pepper) & $\$ 1^{79}$ & $\$ 1^{79}$ & $0.0 \%$ \\
\hline Body Wash (Dial Spring Water) & $\$ 6^{\circ 9}$ & $\$ 6^{\circ 0}$ & $0.0 \%$ \\
\hline \multicolumn{3}{|c|}{ Average change: } & $2.0 \%$ \\
\hline
\end{tabular}

Panel D. Hypothetical (10\%)

Figure 1. Example of Products (various levels), Statistics (1.5 percent), and Hypothetical (10 percent) TREATMENTS, US ONLINE EXPERIMENT

Notes: The Statistics treatment was preceded by the following text: "Before answering, please look at the table below. The table shows indicators used by different government agencies to measure the annual inflation rate-that is, how much prices have changed on average over the last 12 months, from August 1, 2012 to August 1, 2013." The Products treatments were preceded by the following text: "Before answering, please look at the table below. The table shows the price of each listed product on August 1, 2012 and on August 1, 2013 (that is, one year later). These prices were taken from the same branch of a large supermarket chain. The six products that appear in this table were randomly selected from a database containing hundreds of products." The Hypothetical treatment was preceded by the following text: "In this survey we ask you questions about how "prices in general" evolve over time. The following question is meant to assess how comfortable you are with the way these questions are phrased. Please consider the following prices of a hypothetical product at two different moments" and, immediately afterward, included the following question: "What is the approximate price change of this product over this period? Please do not use a calculator, pen, or pencil to calculate the exact figure. We want your best guess from eye-balling these prices." See the questionnaire Appendix for more details. The online Appendix presents examples of the Products treatment for the Argentina Online Experiment.

Source: ${ }^{1}$ Bureau of Labor Statistics; ${ }^{2}$ Bureau of Economic Analysis; ${ }^{3}$ Bureau of Economic Analysis

The products were selected from six broad types of goods (infant formula, bread, pasta and noodle-related products, cereals, sodas, and shampoos and related products). An algorithm selected the products in the specific tables so that the average price changes stayed between -2 percent to 7 percent in 1 percentage point increments for a total of ten tables. The algorithm populated the tables with products of different average price changes. It also verified that other characteristics of the tables were roughly constant, based on the availability of price histories for thousands of products and on detailed information about product characteristics. For instance, every table had one product from each of the six categories of goods, and the goods within each category had similar initial prices across tables (the algorithm selects different brands within product categories, because each brand experiences different price changes). This ensured that the initial price level and the representativeness of the products remained broadly comparable across tables. The information provided 
was entirely truthful, and a note accompanying the table indicated that the products were taken from a large database with information from an existing branch of a large US supermarket chain. 11 There was no indication that the products in the table or the average of price changes were representative or that they reflected actual inflation levels. Respondents in this treatment arm were randomly assigned one of the ten tables with different average price changes, which we indicate in parentheses after the Products treatment arm name in the rest of this paper. Panels A and B in Figure 1 illustrate the -2 percent and 2 percent cases, respectively.

An additional treatment arm consisted of a combination of the previous two pieces of information (i.e., the respondent was shown the table with inflation statistics and one of the tables with prices for specific products). This is the Statistics (1.5 percent) + Products treatment arm, which was designed to test whether the tables with specific prices induced learning over and above the information conveyed by the inflation statistics.

Finally, we included a fourth treatment arm to gauge the degree of spurious learning, which we call the Hypothetical treatment. The respondents were asked to "eyeball" the price change of a product over one year. We phrased the question in terms of the need to assess how comfortable the respondent was with questions about price changes. The table we provided contained only two prices at two points in time (January 1, 2012 and January 1, 2013) without specifying the product. The price of the hypothetical product changed from $\$ 9.99$ to $\$ 10.99$, a price increase of about 10 percent (panel D of Figure 1). If the number we introduced in the information provision stage, which was unrelated to reality, had any impact on stated inflation expectations, it would comprise evidence of spurious learning.

\section{Estimating Learning Rates}

In the following sections, we present some reduced form evidence on how individuals react to randomly assigned information. We compare the raw distribution of inflation expectations (e.g., by means of a histogram) across individuals who were assigned to different treatment groups. The main advantage of this model-free approach is its transparency. Additionally, in this section we introduce a simple learning model that can summarize reactions to the information in a single parameter. These reactions can then be easily compared between experimental samples and information treatments.

We denote an individual's perception of the annual inflation rate over the previous 12 months as $\pi_{i, t}$. In turn, $\pi_{i, t+1}$ represents the individual's expected annual inflation rate over the following 12 months. Individuals use information about (perceived) past inflation to form their expectations about future inflation:

$$
\pi_{i, t+1}=f\left(\pi_{i, t}\right) .
$$

\footnotetext{
${ }^{11}$ The data were scraped from the websites of some of the largest supermarkets in the United States and Argentina as part of the Billion Prices Project at MIT. See Cavallo (2013) for details.
} 
Note that this is a reduced form model of expectations: this forecasting rule could represent an agent with rational expectations, an agent with adaptive expectations, or some other model of expectation formation. 12 None of the experiments that we conduct intend to distinguish between these different interpretations, because we want to estimate a model of learning, not a model of expectation formation.

We consider a linear specification for $f(\cdot)$ :

$$
\pi_{i, t+1}=\mu+\beta \pi_{i, t},
$$

where $\beta$ is the degree of pass-through from inflation perceptions to inflation expectations. A simple forward-looking model like this seems to be a good strategy from the perspective of forming inflation expectations. For example, Atkeson and Ohanian (2001) report that, since 1984, the one-year-ahead inflation forecast of professionals in the United States has been no better than the "native" forecast of the inflation rate over the previous year.

Indeed, this linear specification fits the expectations and perceptions data very well (Jonung 1981). For example, Figure 2 shows a robust linear relationship between perceived past inflation and expected future inflation for our online samples: with a regression coefficient of 0.782 in the United States (panel A) and a regression coefficient of 0.883 in Argentina (panel B). 13 Moreover, a great deal of the variation in inflation expectations can be explained by variation in inflation perceptions: in our US sample, 29 percent of the variation in inflation expectations is due to variation in inflation perceptions, whereas the equivalent figure for our Argentine sample is 60 percent. In other words, a significant fraction of the disagreement about future inflation seems to result from a disagreement about past inflation (see also Blanchflower and MacCoille 2009). Thus, to understand the biases and dispersion in future inflation expectations, we must understand the biases and dispersion in perceptions about past inflation.

The experiments we carried out consist of providing information related to past inflation. Let $\pi_{i, t}^{0}$ denote perceptions prior to the acquisition of new information, and let $\pi_{i, t}^{T}$ denote the signal from the information provided in the experiment. Any learning process (i.e., how individuals combine their prior knowledge and the new information to form their perceptions) can be represented by the following reduced form equation:

$$
\pi_{i, t}=g\left(\pi_{i, t}^{0}, \pi_{i, t}^{T}\right) .
$$

There are several plausible functional forms for $g(\cdot)$. A simple and parsimonious alternative is to assume a Bayesian learning model with Gaussian distribution. Under this model, the prior belief is normally distributed with mean $\pi_{i, t}^{0}$ and

\footnotetext{
${ }^{12}$ The fact that individuals use information about the past to estimate future inflation may be suggestive of the models of adaptive learning (Sargent 1993). However, the use of inflation perceptions to assess future inflation may also be consistent with rational expectations: e.g., some rational expectation models predict that inflation expectations follow an AR(1) process (Barr and Campbell 1997).

${ }^{13}$ These data are for subjects in the control group (i.e., those who were not provided any information about inflation).
} 
Panel A. United States

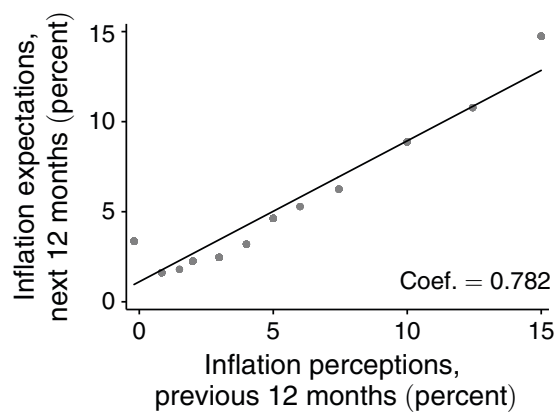

Panel B. Argentina

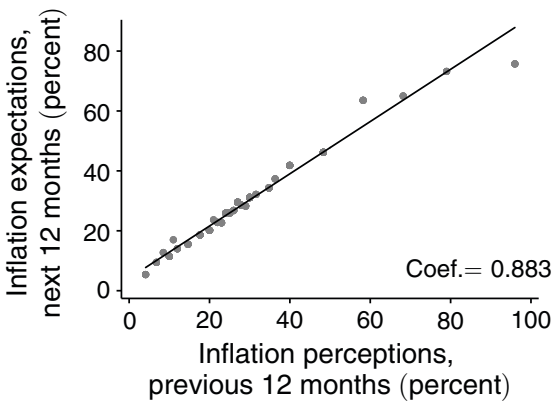

Figure 2. Past Inflation Perceptions versus Future Inflation Expectations, US AND ARgENTINA ONLINE EXPERIMENTS

Notes: The total number of observations are 783 for the United States and 567 for Argentina's sample II. These observations correspond to the control group only in both cases. The figures are binned scatter plots. The darker markers represent the average inflation expectations for quantiles of inflation perceptions (12 quantiles for the United States and 24 for Argentina). The solid line represents the 45 degree line.

standard deviation $\sigma_{i, t}^{0}$ (indeed, the distribution of reported inflation perceptions and expectation is distributed approximately normal). The individual is presented with a signal about average inflation, $\pi_{i, t}^{T}$, which can be interpreted as the price change for one product randomly drawn from the universe of products. The population of price changes for all possible products follows a normal distribution with mean $\pi_{i, t}$ and standard deviation $\sigma_{i, t}^{T}$ this functional form is also roughly consistent with the actual distribution of price changes). By construction, $\pi_{i, t}^{T R E E}$ is the actual inflation level (i.e., the average of price changes for all products). The precision of the signal is given by the inverse of $\sigma_{i, t}^{T}$, which is assumed to be known. Under these assumptions, the posterior belief is distributed normally with the following mean and variance:

$$
\begin{aligned}
\pi_{i, t} & =\frac{\left(\frac{1}{\sigma_{i, t}^{0}}\right)^{2}}{\left(\frac{1}{\sigma_{i, t}^{0}}\right)^{2}+\left(\frac{1}{\sigma_{i, t}^{T}}\right)^{2}} \pi_{i, t}^{0}+\frac{\left(\frac{1}{\sigma_{i, t}^{T}}\right)^{2}}{\left(\frac{1}{\sigma_{i, t}^{0}}\right)^{2}+\left(\frac{1}{\sigma_{i, t}^{T}}\right)^{2}} \pi_{i, t}^{T}, \\
\sigma_{i, t} & =\sqrt{\frac{\left(\sigma_{i, t}^{0} \cdot \sigma_{i, t}^{T}\right)^{2}}{\left(\sigma_{i, t}^{0}\right)^{2}+\left(\sigma_{i, t}^{T}\right)^{2}}} .
\end{aligned}
$$

That is, individuals update their perceptions based on an average between their prior beliefs and the realized signal:

$$
\pi_{i, t}=\left(1-\alpha_{i, t}\right) \pi_{i, t}^{0}+\alpha_{i, t} \pi_{i, t}^{T},
$$

where $\alpha_{i, t}$, the weight assigned to the new information, decreases with the accuracy of the prior belief $1 / \sigma_{i, t}^{0}$ and increases with the accuracy of the signal $1 / \sigma_{i, t}^{T}$. 
If $\sigma_{i, t}^{0}$ and $\sigma_{i, t}^{T}$ are constant across individuals, then $\alpha$ is also constant across individuals. Replacing this expression in equation (2), the linearized version of the forward-looking equation, results in the following expression:

$$
\pi_{i, t+1}=\gamma_{0}+\underbrace{\gamma_{1}}_{\beta} \pi_{i, t}^{0}+\underbrace{\gamma_{2}}_{\alpha \beta}\left(\pi_{i, t}^{T}-\pi_{i, t}^{0}\right)+\varepsilon_{i, t+1} .
$$

Note that the three elements in regression equation (6) are all observed in our experimental data: $\pi_{i, t+1}$ is the respondent's stated inflation expectation (posttreatment); $\pi_{i, t}^{0}$ is the respondent's stated past inflation perception (pretreatment); and $\pi_{i, t}^{T}-$ $\pi_{i, t}^{0}$ is the difference between the signal provided in the informational treatment and the prior belief (defined as zero for the control group). Thus, we can regress $\pi_{i, t+1}$ on $\pi_{i, t}^{0}$ and $\pi_{i, t}^{T}-\pi_{i, t}^{0}$ to estimate $\hat{\gamma}_{1}$ and $\hat{\gamma}_{2}$, and then use those parameters to estimate $\hat{\alpha}$ and $\hat{\beta}$ using the formulas $\hat{\beta}=\hat{\gamma}_{1}$ and $\hat{\alpha}=\hat{\gamma}_{2} / \hat{\gamma}_{1}$. We use the Delta Method to obtain the standard errors of $\hat{\alpha}=\hat{\gamma}_{2} / \hat{\gamma}_{1} \cdot$. $^{14}$

The parameter $\beta$ represents the rate of pass-through from perceptions of past inflation to future inflation expectations. The parameter $\alpha$ captures the weight that the individual assigns to the information provided in the experiment, relative to that individual's prior belief. Intuitively, if the individual started with a prior belief of $\pi_{i, t}^{0}$ and if the informational treatment provides a signal that inflation is $\pi_{i, t}^{T}$, then the posterior belief can be expected to be between $\pi_{i, t}^{0}$ and $\pi_{i, t}^{T}$, and the parameter $\alpha$ reflects how much closer $\pi_{i, t}$ is to $\pi_{i, t}^{T}$ relative to $\pi_{i, t}^{0}$.

The following example illustrates the intuition behind our empirical model. Let us assume that, among individuals who receive no information from us, the correlation between inflation perceptions and expectations is 0.5 . That is, for each 1 percent increase in perceived past inflation, an individual believes that future inflation will be 0.5 percent higher. Now assume that we take a group of individuals who believed that past inflation was 10 percent, and we randomly provide some of them a signal that past inflation was 20 percent. If, relative to the control group, individuals who received the signal believe that future inflation is going to be 1 percent higher, then the information led them to believe that past inflation was 2 percent higher (i.e., 1/0.5). In other words, the signal that past inflation was actually 20 percent increased their beliefs about past inflation from 10 percent to 12 percent. This indicates that, in forming their posterior beliefs, they assigned a 0.8 weight to the prior belief of 10 percent and a 0.2 weight to the signal of 20 percent (i.e., $12 \%=0.8$ $\times 10 \%+0.2 \times 20 \%)$.

This model of Bayesian learning makes several additional predictions that can be directly tested with the data. For instance, this model predicts that confidence in the posterior belief, $\sigma_{i, t}$, should be higher for individuals who were provided with relevant information than for those who did not receive any information. We present results for these tests in the results section and in the Appendix. 5

\footnotetext{
${ }^{14}$ One assumption is that the above OLS regression yields an unbiased estimate for $\beta$. Because $\pi_{i, t}^{0}$ is not randomized, at least in principle, $\beta$ could suffer from omitted variable bias, which in turn could bias the estimation of $\alpha$.

${ }^{15}$ Armantier et al. (2016) also provide related tests of Bayesian learning in the context of household perceptions about inflation.
} 


\section{Disentangling Genuine from Spurious Learning}

A potential issue with our results is that, even if we find that the information provided has an effect on stated inflation expectations, individuals' reactions to this information may be spurious. In this section, we present a framework to quantify how much of $\alpha$ responds to genuine learning and how much to spurious learning.

Our first (and preferred) strategy consists of using data on the evolution of expectations obtained through follow-up surveys taken months after the original information provision. Numerical anchoring is, by definition, very short-lived, so we do not expect it to explain effects on beliefs measured months after the information was provided. Regarding interviewer pressure, it is most likely that subjects will not remember the information that was provided to them months ago, so they should not be subject to pressure to agree with the interviewer.

Let $\pi_{i, t+1}^{\text {follow-up }}$ denote the inflation expectations elicited in a follow-up survey conducted months after the initial experiment, in which we did not provide any new information and we did not remind the subject about information provided in the past. Consider this new forward-looking equation: $\pi_{i, t+1}^{\text {follow }-u p}=\mu_{F U}+\beta_{F U} \pi_{i, t}$, where $\beta_{F U}$ is the degree of pass-through from inflation perceptions, as stated in the original survey, to inflation expectations stated in the follow-up survey. The estimate of $\beta_{F U}$ should be lower than $\beta$, because $\beta_{F U}$ is the product of $\beta$ (i.e., pass-through from perceptions to expectations) and the pass-through from inflation perceptions in the first survey to inflation perceptions in the second survey (which is expected to be lower than one because individuals should have acquired more information in the meantime). In other words, for this estimate, we do not need to assume that individuals do not learn new information between the two surveys, because the parameter $\beta_{F U}$ accounts for this assumption.

If we combine the new forward-looking equation with the learning equation (5), we obtain the following:

$$
\pi_{i, t+1}^{\text {follow-up }}=\gamma_{0}+\underbrace{\gamma_{1}}_{\beta_{F U}} \pi_{i, t}^{0}+\underbrace{\gamma_{2}}_{\alpha \beta_{F U}}\left(\pi_{i, t}^{T}-\pi_{i, t}^{0}\right)+\varepsilon_{i, t+1} .
$$

In other words, we can use the same estimation procedure with $\pi_{i, t+1}^{\text {follow }-u p}$ instead of $\pi_{i, t+1}$ as the dependent variable. Intuitively, if in the original survey the information provided by the experimenter truly affected the individual's posterior belief about past inflation, then (after properly accounting for the rate of information renewal) this effect should persist in beliefs elicited at future points in time. Because this new estimation strategy should remove spurious learning (at least to some degree), the

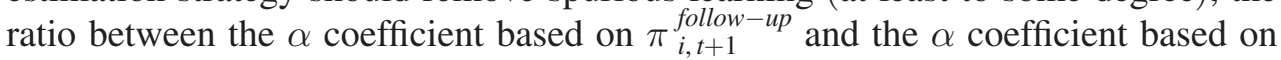
$\pi_{i, t+1}$ can provide an estimate of the share of learning that is genuine rather than spurious.

We can provide an intuitive explanation of what our estimate captures. Among individuals who did not receive any information from us, suppose that we observe that each extra percentage point in perceived inflation today translates, on average, to about 0.5 additional percentage points of inflation expectations two months from now. If an informational treatment truly convinced a subject today that inflation 
expectations will be 1 percentage point higher, we should observe an increase in inflation expectations of 0.5 percentage points, as measured two months later. If, though, the information induced only a 0.25 increase in inflation expectations two months later, then we would conclude that half of the learning was genuine. If the information did not induce any changes in inflation expectations two months after the treatment, then all learning would be deemed spurious.

The second strategy is based on individuals' perceptions and expectations regarding other economic indicators that are closely related to inflation. In our experiments, we collected information on perceptions about the expected nominal interest rate over the next 12 months, which, just like inflation expectations, was elicited after the experimental information provision. Let $i_{i, t+1}$ denote the expectation about the nominal annual interest rate. The new forward-looking equation is $i_{i, t+1}=\mu_{I}+$ $\beta_{I} \pi_{i, t}$, where $\beta_{I}$ is the degree of pass-through from inflation perceptions to interest rate expectations. If we combine the new forward-looking equation with the learning equation (5), we obtain the following:

$$
i_{i, t+1}=\gamma_{0}+\underbrace{\gamma_{1}}_{\beta_{I}} \pi_{i, t}^{0}+\underbrace{\gamma_{2}}_{\alpha \beta_{I}}\left(\pi_{i, t}^{T}-\pi_{i, t}^{0}\right)+\varepsilon_{i, t+1} .
$$

Again, this corresponds to using $i_{i, t+1}$ instead of $\pi_{i, t+1}$ as the dependent variable in our learning regression. Comparing the estimated $\alpha$ coefficients in the two specifications provides a second way to quantify genuine versus spurious learning. The intuition for this test is very similar to that of the first test. Assume that among individuals in the control group, respondents who report expecting a 1 percentage point increase in inflation also report a future nominal interest rate that is 0.3 percentage points higher. If an informational treatment truly convinces a subject that future inflation will be 1 percentage point higher, it should also convince that individual that the future nominal interest rate will be 0.3 percentage points higher. However, if the information induced only a spurious effect on inflation expectations, then it would have no impact on interest rate expectations (or any other nominal variables intrinsically related to inflation).

\section{Results from Online Experiments in the United States and Argentina}

\section{A. Subject Pool and Descriptive Statistics}

In the United States, we recruited subjects from Amazon's Mechanical Turk (AMT) online marketplace during September 2013. We followed several best practices for recruiting individuals for online surveys and experiments using AMT to ensure high quality responses (see, for instance, Crump, McDonnell, and Gureckis 2013). In Argentina, a first sample was collected through an online survey of college graduates. The second, larger sample is based on an established public opinion research firm that carries out a quarterly online survey of adults in Argentina. See the online Appendix for further details about the samples.

According to the Consumer Price Index (CPI) reported by the Bureau of Labor Statistics (BLS), the annual inflation in the United States for the five years prior to 
Panel A. United States

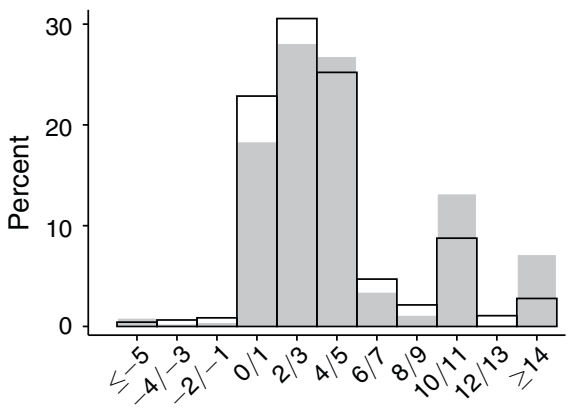

Inflation expectations, next 12 months

US online survey

$\square$ U. of Michigan survey
Panel B. Argentina

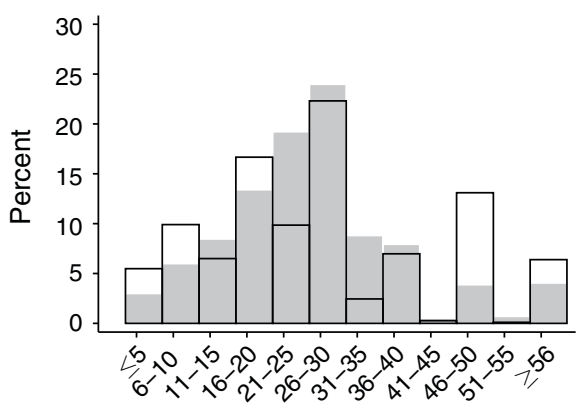

Inflation expectations, next 12 months

Argentina online survey

UTDT sample

Figure 3. Comparison of Inflation Expectations between US and Argentina Online Experiment Samples AND THIRD-PARTY SAMPLES

Notes: Both figures plot the distribution of inflation expectations for the following 12 months for each country according to two different sources. Panel A presents the distribution for the United States for the control group of our US online experiment sample $(N=697$ September 2013 observations only) and for the University of Michigan's Survey of Consumers ( $N=468$ September 2013 wave). Panel B presents the distribution of inflation expectations for Argentina for the control group of our Argentina online experiment sample II (opinion poll, $N=567)$ and for the Universidad Torcuato Di Tella's Encuesta de Percepciones de Inflacion $(N=1,878)$, both for April 2013.

our study (2008-2012) was, on average, 1.8 percent. In the online survey, the mean for inflation perceptions was 5.07 percent. In the control group, the mean for inflation expectations was 5.08 percent. In Argentina, the average rate for 2008-2012 was also stable but around 22.5 percent. In the larger sample, the mean inflation perception was 27.8 percent, and the mean inflation expectation in the control group was 28.4 percent.

Our US sample is younger and more educated than the US average, while our Argentine sample is more educated than the country average (the online Appendix provides a comparison of characteristics with population averages). In any case, as shown in the online Appendix, the results are similar if we re-weight the observations to make them representative on observables. In turn, Figure 3, panel A, compares the distribution of inflation expectations in our US online experiment (for the control group) to the University of Michigan's Survey of Consumers. Besides originating in different samples, there are several methodological differences between the two survey questions capturing expected inflation. Despite these differences, the distribution of inflation expectations in the two samples are very similar. For example, the median expectation is just 1 percentage point higher in our online sample (4 percent) than in the University of Michigan survey (3 percent), and the interquartile range is just 1 percentage point wider in our sample ( 2 percent-6 percent, compared to 2 percent-5 percent).

Figure 3, panel B, provides a similar comparison for the Argentine data. In Argentina, there is no nationally representative survey equivalent to the Michigan's Survey of Consumers or the Federal Reserve Bank of New York's Survey of 
Consumer Expectations. Instead, Figure 3.b compares our Argentine sample to the Survey of Consumer Expectations conducted by the University Torcuato Di Tella. This survey is less comparable to our online survey for several reasons, one of which is because the language of the inflation expectation question is different. Despite these differences, the distribution of inflation expectation is roughly comparable across these two surveys.

In the United States, the final sample includes 3,945 individuals, with 783 in the Control group, 807 in the Statistics (1.5 percent) treatment, 763 in the Products treatment (10 tables with average price changes from -2 percent to 7 percent in 1 percentage point increments within this treatment), 804 in the Products + Statistics (1.5 percent) combined treatment (same 10 tables as above), and 788 in the Hypothetical treatment. In Argentina, the first sample yielded 691 observations, 182 of which were assigned to the control, 161 to Statistics (24 percent). 16 and 348 to the Products arm (with average price changes of 19 percent, 24 percent, and 29 percent). The second sample yielded 3,653 subjects, with 567 subjects assigned to the control group and the rest to the Products arm (with average price changes ranging from 16 percent to 34 percent, in 1 percentage point increments).

\section{B. Rational Inattention Test}

In this section, we discuss the rational inattention test, which relies on the comparison of learning rates between the United States and Argentina.

In the five years before our study (2008-2012), the annual inflation rate in the United States was stable and averaged 1.8 percent. The average rate in Argentina was also stable but around 22.5 percent. Thus, the cost of ignoring inflation in Argentina was substantially higher. For example, individuals must rely on good information on inflation prospects in drawing up contracts, because it is illegal to index such contracts (labor, real estate, etc.), or rely on more stable foreign currencies. ${ }^{17}$ Opinion polls in Argentina at the time of the survey systematically indicated inflation as one of the population's primary concerns. ${ }^{18}$ Inflation statistics were mentioned on offline and online news outlets on a regular basis, frequently making the front page of newspapers. According to the rational inattention model (Sims 2005, Veldkamp 2011), individuals in Argentina should be more informed and consequently have stronger prior beliefs about past inflation than their US counterparts.

Figure 4 summarizes the reduced form evidence from the online experiment (see the online Appendix for more detailed outputs by different treatment arms). All panels in this figure present the distribution of inflation expectations for two treatment arms, in which one arm is always the control group (the histograms accumulate the

\footnotetext{
${ }^{16}$ The value provided in the Statistics treatment arm (and reported therein) represents the average inflation estimates of private consultancies, research centers, and provincial public statistical agencies, as compiled and computed by opposition parties in the Argentine Congress since the intervention of the national statistical agency in Argentina in 2012 (Cavallo 2013). These are the statistics that individuals used on a regular basis (for more details, see Cavallo, Cruces, and Perez-Truglia 2016).

${ }^{17}$ See Cavallo, Cruces, and Perez-Truglia (2016) for more details on the Argentine macroeconomic and institutional context at the time of our experiments.

${ }^{18}$ For our opinion poll sample, 40.7 percent of those in our control group selected inflation as one of the three main concerns for the country.
} 
Panel A. United States

Al. Control and Statistics (1.5\%)

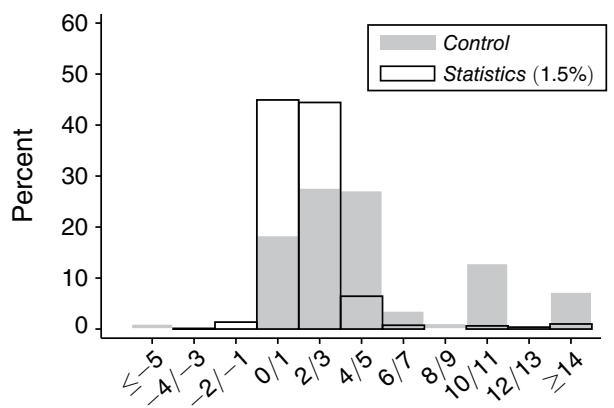

Inflation expectations, next 12 months (percent) Note: ES test $p$-value: $<0.01$.
All. Control and Products ( $2 \%$ and $3 \%)$

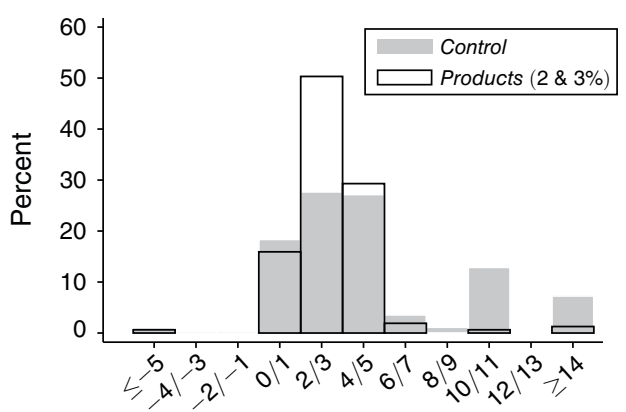

Inflation expectations, next 12 months (percent) Note: ES test $p$-value: $<0.01$.

Panel B. Argentina

BI. Control and Statistics (24\%), sample I

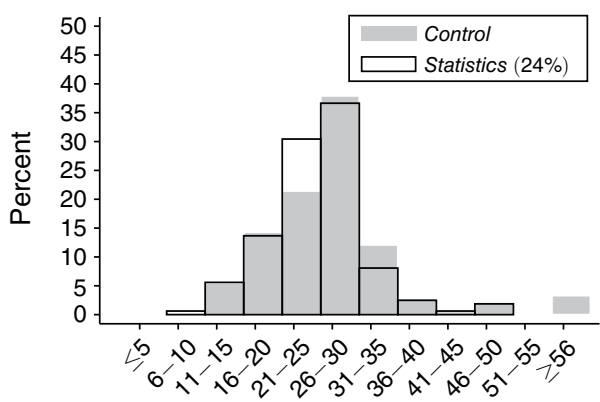

Inflation expectations, next 12 months (percent) Note: ES test $p$-value: $<0.13$.
BII. Control and Statistics (24\%), sample I

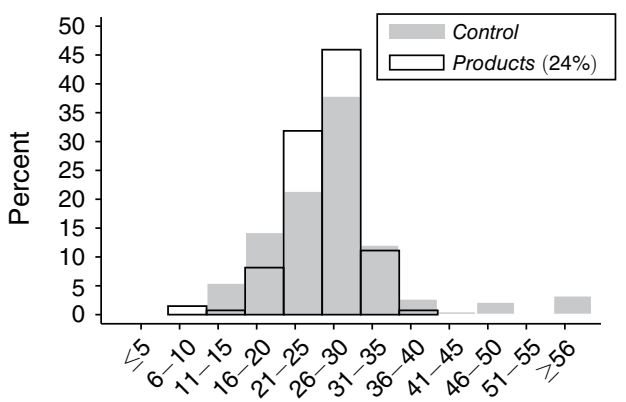

Inflation expectations, next 12 months (percent) Note: ES test $p$-value: $<0.01$.

Figure 4. Reduced Form Evidence: Rational Inattention Test, US and Argentina Online Experiments

Notes: For panel A, we use the US online experiment sample, with 783 observations from the Control group, 807 from the Statistics (1.5 percent) treatment and 156 observations from the Products ( 2 percent) and Products ( 3 percent) groups. For panel B, we use observations from the Argentina online experiment sample I, with 182 observations from the Control group, 161 observations from the Statistics (24 percent) group, and 135 observations from the Products (24 percent) group. ES is the Epps-Singleton characteristic function test of equality of two distributions. The histograms are censored at -5 percent and 15 percent (inclusive) in panel A and at 5 percent and 55 percent in panel $\mathrm{B}$, but these bins represent the cumulative observations below the minimum and above the maximum for each country.

observations below -5 percent and above 15 percent in the extreme bars). Each panel in Figure 4 reports the results from an Epps-Singleton (ES) two-sample test using the empirical characteristic function, which is a version of the KolmogorovSmirnov test of equality of distributions that is valid for discrete data (Goerg and Kaiser 2009). All pairwise differences are statistically significant at the 1 percent level, indicating that our experimental subjects significantly reacted to the inflation provided by us.

We start with the reduced form results for the United States. Figure 4, panel AI presents the results for the Statistics (1.5 percent) treatment, which consisted of providing the respondent solely with a table of statistics about past inflation. According 
to the Bayesian learning model, providing a signal about inflation should shift the distribution of inflation expectations (relative to the control group) towards the value of the signal, and it should produce a more concentrated distribution of expectations. Consistent with this prediction, this signal shifts the distribution of expectations towards 1.5 percent and makes the distribution of expectations less dispersed.

Figure 4, panel AII shows the effects of the Products ( 2 percent-3 percent) treatments (the online Appendix shows the results for the rest of the Products groups). Consistent with the learning model, the signal that supermarket products increased 2 percent -3 percent shifted inflation expectations towards this range and reduced the dispersion of expectations.

Turning to the reduced form results for Argentina, Figure 4, panels BI and BII present the results that are equivalent to those in Figure 4, panels AI and AII for the United States. The results in Argentina are qualitatively identical to those from the US experiment: providing a signal about inflation shifted the distribution of inflation expectations toward the value of the signal and led to a more concentrated distribution of expectations.

Although the effects of Statistics and Products information are qualitatively identical between the United States and Argentina, the rational inattention test relies on the quantitative comparison between the two countries. To facilitate such comparison, Table 1 presents the estimates of the learning rates, based on the Bayesian learning model introduced in Section IC, with results from the US experiment in panel A and results from the Argentine experiment in panel B. The table reports the values of $\alpha$ and $\beta$ from equation (6). As previously discussed, $\beta$ can be interpreted as the degree of pass-through between perceptions of past inflation and expectations of future inflation, and $\alpha$ as the weight placed by the respondents on the information provided in the experiment, with $(1-\alpha)$ being the weight placed on respondents' prior belief about past inflation.

Column 1 from Table 1, panel A, reports that, in the United States, the learning rate $(\alpha)$ in the Statistics (1.5 percent) treatment was 0.838 ( $p$-value $<0.01)$, whereas the weight given to its equivalent in the Products treatment was 0.689 ( $p$-value $<0.01$ ). In other words, US subjects assigned a much greater weight to the information provided by the experiment than to their own prior belief. In turn, column 1 from Table 1, panel B, reports that, in the first Argentine sample, the estimated $\alpha$ is 0.432 $(p$-value $<0.01)$ for the Statistics treatment and $0.458(p$-value $<0.01)$ for the Products treatment (column 2 shows a similar learning rate of 0.494 for the Products treatment in the second Argentine sample). 19 Consistent with the prediction of the rational inattention model, US subjects revealed to be less informed about inflation, insofar as they assigned between 95 percent (i.e., $\frac{0.838-0.432}{0.432}$ ) and 51 percent (i.e., $\left.\frac{0.689-0.458}{0.458}\right)$ more weight to the information about statistics and supermarket products, relative to the Argentine subjects.

\footnotetext{
${ }^{19}$ The similar results for our college graduates sample I, all of whom had at least some basic training in economics and most of whom were professional economists or accountants, and our public opinion poll sample II suggest that economic literacy does not drive our findings (see also Burke and Manz 2011).

${ }^{20}$ This evidence is consistent with related evidence from Coibon, Gorodnichenko, and Kumar (2015) on firms' lack of incentives to collect and process information on macroeconomic conditions (i.e., rational inattention) and its impact on firms' inflation perceptions.
} 
Table 1-Estimates of Learning Rates, Online ExPeriments

\begin{tabular}{|c|c|c|c|c|c|}
\hline & $\begin{array}{c}\pi_{i, t+1} \\
(1)\end{array}$ & $\begin{array}{c}\pi_{i, t+1} \\
(2)\end{array}$ & $\begin{array}{c}\pi_{i, t+1} \\
(3)\end{array}$ & $\begin{array}{c}\pi_{i, t+1}^{\text {follow-up }} \\
\text { (4) }\end{array}$ & $\begin{array}{c}i_{i, t+1} \\
(5)\end{array}$ \\
\hline \multicolumn{6}{|l|}{ Panel A. United States } \\
\hline$\beta$ & $\begin{array}{c}0.757 \\
(0.033)\end{array}$ & $\begin{array}{c}0.817 \\
(0.058)\end{array}$ & $\begin{array}{c}0.814 \\
(0.046)\end{array}$ & $\begin{array}{c}0.438 \\
(0.055)\end{array}$ & $\begin{array}{c}0.291 \\
(0.040)\end{array}$ \\
\hline$\alpha$-Products & $\begin{array}{c}0.689 \\
(0.036)\end{array}$ & $\begin{array}{c}0.449 \\
(0.050)\end{array}$ & $\begin{array}{c}0.697 \\
(0.045)\end{array}$ & $\begin{array}{c}0.336 \\
(0.150)\end{array}$ & $\begin{array}{c}0.499 \\
(0.135)\end{array}$ \\
\hline$\alpha$-Statistics & $\begin{array}{c}0.838 \\
(0.034)\end{array}$ & $\begin{array}{c}0.283 \\
(0.063)\end{array}$ & $\begin{array}{c}0.799 \\
(0.058)\end{array}$ & $\begin{array}{c}0.360 \\
(0.138)\end{array}$ & $\begin{array}{c}0.314 \\
(0.212)\end{array}$ \\
\hline$\alpha$-Hypothetical & $\begin{array}{c}0.232 \\
(0.027)\end{array}$ & & $\begin{array}{c}0.215 \\
(0.046)\end{array}$ & $\begin{array}{c}-0.021 \\
(0.092)\end{array}$ & $\begin{array}{c}0.131 \\
(0.112)\end{array}$ \\
\hline Observations & 3,141 & 1,587 & 1,073 & 1,073 & 3,141 \\
\hline Simultaneous treatments & No & Yes & No & No & No \\
\hline \multicolumn{6}{|l|}{ Panel B. Argentina } \\
\hline$\beta$ & $\begin{array}{c}1.138 \\
(0.118)\end{array}$ & $\begin{array}{c}0.902 \\
(0.042)\end{array}$ & $\begin{array}{c}0.963 \\
(0.041)\end{array}$ & $\begin{array}{c}0.754 \\
(0.086)\end{array}$ & $\begin{array}{c}0.155 \\
(0.035)\end{array}$ \\
\hline$\alpha$-Products & $\begin{array}{c}0.458 \\
(0.062)\end{array}$ & $\begin{array}{c}0.494 \\
(0.027)\end{array}$ & $\begin{array}{c}0.456 \\
(0.037)\end{array}$ & $\begin{array}{c}0.208 \\
(0.094)\end{array}$ & $\begin{array}{c}0.468 \\
(0.133)\end{array}$ \\
\hline$\alpha$-Statistics & $\begin{array}{c}0.432 \\
(0.098)\end{array}$ & & & & \\
\hline Observations & 691 & 3,653 & 1,320 & 1,320 & 3,373 \\
\hline Sample (experts, online) & I & II & II & II & II \\
\hline
\end{tabular}

Notes: Heteroskedasticity robust standard errors are in parentheses. The $\alpha$ and $\beta$ coefficients are obtained from the regression given by equation (6), Section IC: $\pi_{i, t+1}=\gamma_{0}+\gamma_{1} \pi_{i, t}^{0}+$ $\gamma_{2}\left(\pi_{i, t}^{T}-\pi_{i, t}^{0}\right)$, where $\pi_{i, t}^{0}$ is the respondent's stated inflation perception, $\pi_{i, t}^{T}$ is the mean inflation provided in the treatment, and $\pi_{i, t+1}$ is the posttreatment inflation expectation $\left(\pi_{i, t+1}\right)$. We estimate $\hat{\alpha}$ and $\hat{\beta}$ by running this linear regression and setting $\hat{\gamma}_{1}=\hat{\beta}$ and $\hat{\alpha}=\frac{\hat{\gamma}_{1}}{\hat{\gamma}_{2}}$ (standard errors of this ratio computed with the Delta Method). The parameter $\beta$ represents the rate of pass-through from perceptions of past inflation to future inflation expectations. The parameter $\alpha$ captures the weight the individual assigns to the information provided in the experiment relative to her prior belief. In panel A, the results presented in column 2 represent the case of the Products + Statistics (1.5 percent) combined treatment, in which treated individuals received two pieces of information simultaneously. In both panels, the dependent variable in columns 1 to 3 is inflation expectations (for the following 12 months) at the time of the original survey, with the sample restricted in column 3 to a subset of respondents who were reinterviewed after the original survey (two months later in the US online experiment and four months later in Argentina). The dependent variable in column 4 is inflation expectations (for the following 12 months) at the time of that follow-up interview. The dependent variable in column 5 is the expected interest rate (for the following 12 months) in the original survey. For the number of observations in each treatment group, please refer to Section IIIA.

Source: The source for the data in panel A is the US online experiment sample. The source for the data in panel B is the Argentina online samples I (college graduates) and II (opinion poll).

A potential confounding factor is the general loss of credibility of price data in Argentina after the manipulation of official statistics for the period 2007-2015 (Cavallo 2013; Cavallo, Cruces, and Perez-Truglia 2016). Although we used an unofficial private sector indicator that was widely reported in the media and that became the de facto consensus figure for inflation during this period, [2] economic

\footnotetext{
${ }^{21}$ This unofficial index was computed by members of the opposition in the Argentine Congress and was constructed as an average of private sector indicators.
} 
agents in Argentina might have become wary of all economic indicators. However, although this may explain why Argentines react less to inflation statistics than Americans, it does not explain why Argentines react less to supermarket prices than Americans. Another confounding factor could be that the difference in learning rates between countries could be explained by differences in characteristics of the subject pools. However, this explanation seems unlikely for at least two reasons. First, the observable characteristics (e.g., gender, age, education) are fairly similar across the two countries.2 Second, as shown in Section ID, the heterogeneity in learning rates by gender, education, and other characteristics are an order of magnitude smaller than the difference in learning rates across the two countries. A last confounding factor could be that differences in learning rates are not due to differences in inflation levels but rather due to differences in the volatility of inflation across the two countries. This explanation seems unlikely for at least two reasons. First, inflation levels were relatively stable in both Argentina and the United States in the five years prior to our study. Second, even if Argentine inflation was deemed as more unstable, that would lead to an underestimation of our results, insofar as individuals should react more to new information in volatile contexts.

\section{Irrational Learning Test}

In this section, we test whether individuals use less accurate information on inflation even when more accurate information is readily available.

Figure 5, panels C and D, present histograms corresponding to the effects of the treatments Products (0 percent) and Products (1 percent) (panel C), and Products ( 2 percent) and Products ( 3 percent) (panel D) on inflation expectations in the US online experiment sample. These figures illustrate how individuals react to different signals about supermarket prices. Relative to the control group, the treatment groups that received signals that supermarket prices had increased 0 percent and 1 percent are more likely to state inflation expectations in this range: the proportion stating 0-1 percent more than doubles, compared to that of the control group (Figure 5, panel C). The reaction is similar to the signals of price increases of 2 percent and 3 percent: this information increases the likelihood that individuals report inflation expectations close to the 2-3 percent range (Figure 5, panel D).

Figure 6 panel AI, provides further evidence about the effects of the Products treatment arm on inflation expectations in the United States. Relative to the control group, each bar represents the effect of each of the ten sub-treatments (with average annual price changes in the tables ranging from -2 percent to 10 percent on the horizontal axis) on average inflation expectations. This figure indicates that each percentage point increase in the average price change reported on the table of products increased the average inflation expectations for about 0.5 percentage points. Figure 6, panel BI shows that, as in Figure 6, panel AI for the United States, average inflation expectations in Argentina responded significantly to the average price changes shown in the table of supermarket products.

\footnotetext{
${ }^{22}$ See the online Appendix for more details.
} 
Panel A. Control and Statistics (1.5\%)

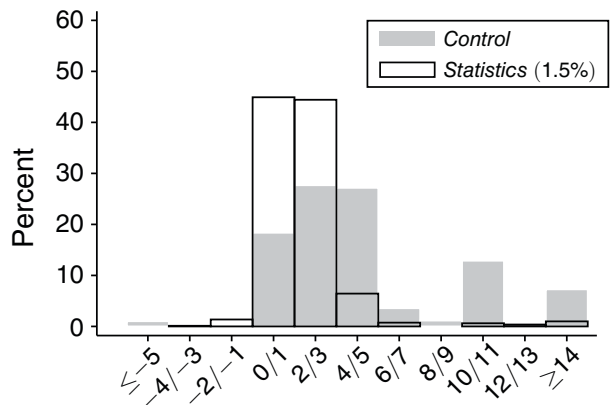

Inflation expectations, next 12 months (percent) Note: ES test $p$-value: $<0.01$.

Panel C. Control and Products ( $0 \%$ and $1 \%$ )

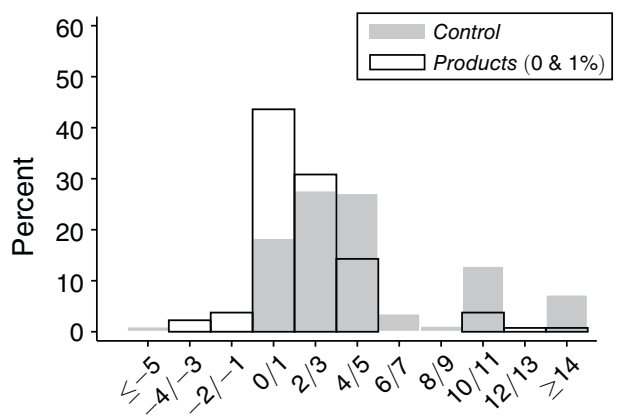

Inflation expectations, next 12 months (percent) Note: ES test $p$-value: $<0.01$.

Panel E. Control and Statistics (1.5\%) + Products $(0 \%$ and $1 \%)$

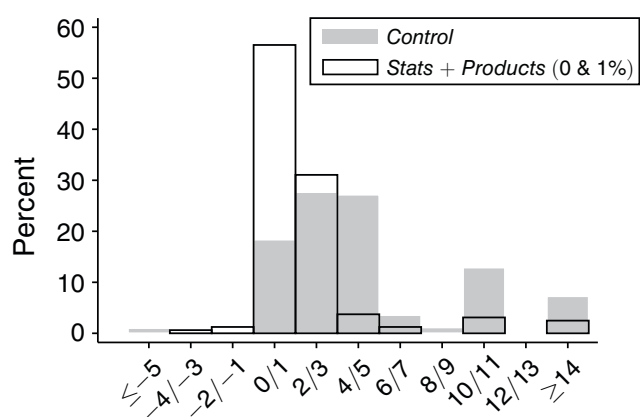

Inflation expectations, next 12 months (percent) Note: ES test $p$-value: $<0.01$.
Panel B. Control and Hypothetical (10\%)

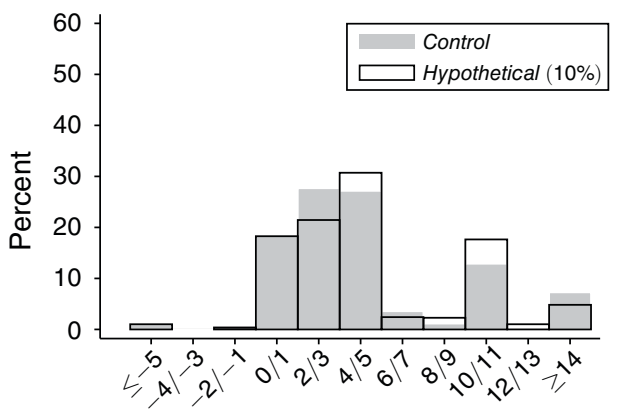

Inflation expectations, next 12 months (percent) Note: ES test $p$-value: $<0.01$.

Panel D. Control and Products (2\% and $3 \%$ )

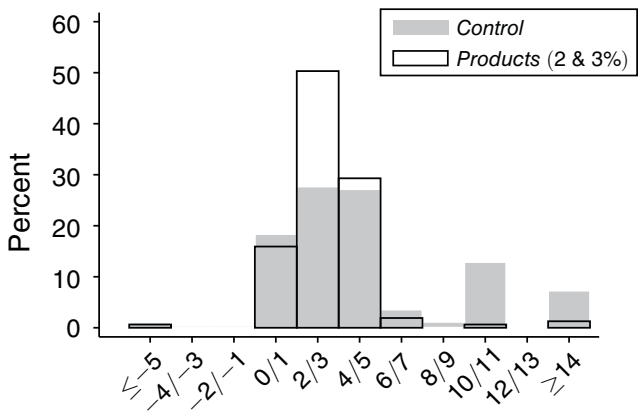

Inflation expectations, next 12 months (percent) Note: ES test $p$-value: $<0.01$.

Panel F. Control and Statistics (1.5\%) + Products $(2 \%$ and $3 \%)$

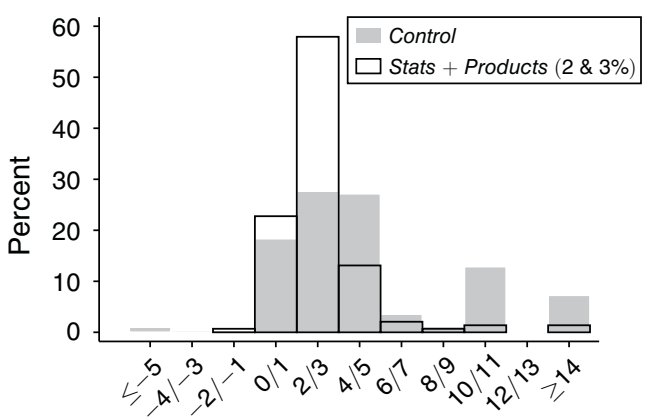

Inflation expectations, next 12 months (percent) Note: ES test $p$-value: $<0.01$.

Figure 5. Reduced Form Evidence: Irrational Learning and Spurious Learning Tests, US ONLINE EXPERIMENT

Notes: The total number of observations for the US online experiment is 3,945, with 783 from the Control group, 807 from the Statistics (1.5 percent) treatment, 763 from the Products treatment (10 tables with average price changes from -2 percent to 7 percent in 1 percentage point increments within this treatment), 804 from the Products + Statistics (1.5 percent) combined treatment (same 10 tables as above), and 788 from the Hypothetical treatment. Panels C and E pool observations from the 0 percent and 1 percent average product price change tables for the Products (panel C) and Products + Statistics (1.5 percent) (panel E) treatments; panels D and F pool those from the 2 percent and 3 percent tables for the Products (panel D) and Products + Statistics (1.5 percent) (panel F) (see examples of these treatments in Figure1). ES is the Epps-Singleton characteristic function test of equality of two distributions. 
Al. Effects on inflation expectations

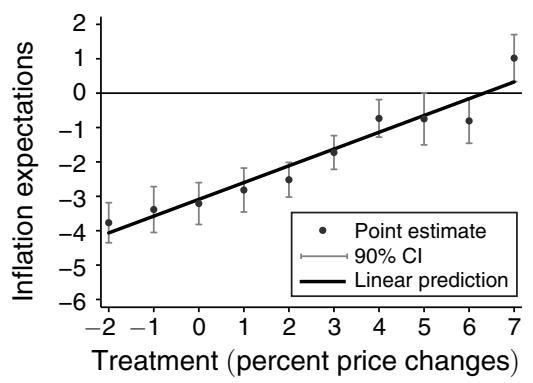

All. Effects on confidence in inflation expectations (Higher is more confident)

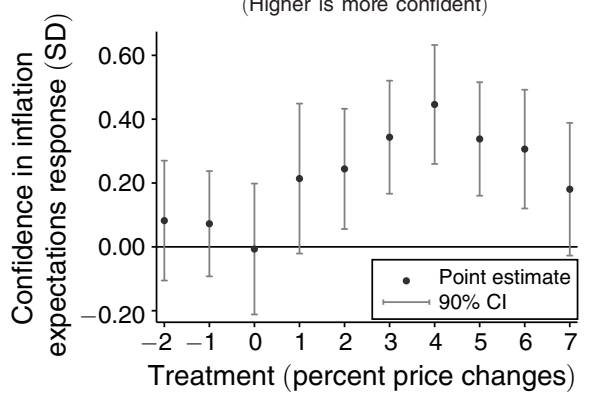

Panel B. Argentina

BI. Effects on inflation expectations

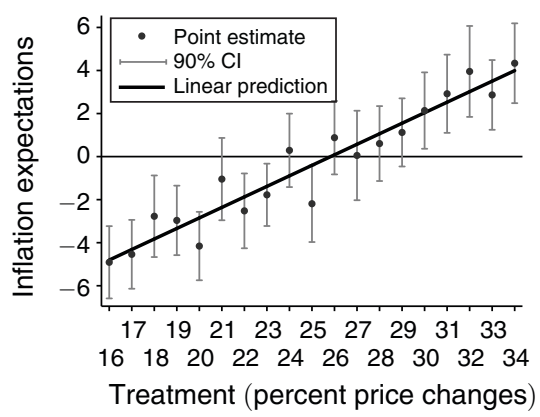

BII. Effects on confidence in inflation expectations (Higher is more confident)

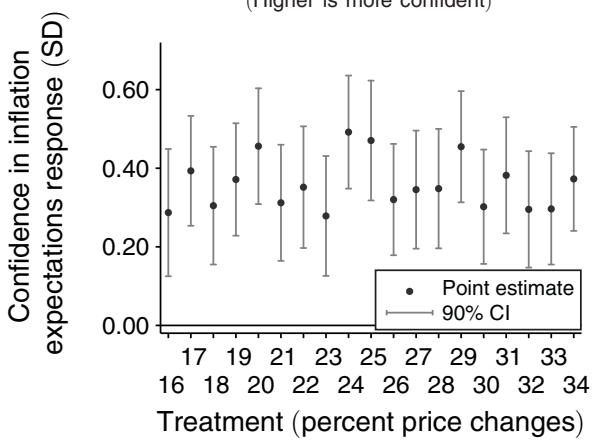

Figure 6. Effects of Products Treatments, US and Argentina Online Experiments

Notes: The results in panel A were obtained from the US online experiment sample, with a total of 1,546 observations (783 from the control group and 763 from 10 variations of Products treatment). The results in panel B correspond to the Argentina Online Experiment sample II, with a total of 3,686 observations (567 from the control group and 146-181 from each of the 19 Products treatment groups). Each bar represents the point estimate of the effect of the specific sub-treatment (average product price changes in the table presented) compared to the control group, with confidence intervals computed with robust standard errors. The confidence variable from panels AII and BII corresponds to the answer to a question about respondents' self-confidence on their inflation expectations, with higher values denoting higher confidence, and standardized to have a standard deviation of 1 .

However, it is possible that individuals pay attention to those signals only because they do not observe their ideal signals, such as inflation statistics. In the treatment arm Statistics (1.5 percent) + Products, experimental subjects were provided with the table of statistics for past annual inflation averaging 1.5 percent and, immediately afterward, they were presented with one of the Products tables with the price changes of supermarket products. Relative to the average price change from a random set of six products, inflation statistics are much more precisely estimated. Thus, when confronted with these two pieces of information, we expect an economic professional to put all weight on the statistics information and ignore the supermarket prices information. In other words, the null hypothesis of rational learning predicts that the Statistics (1.5 percent) + Products ( 0 percent) and Statistics (1.5 percent $)+$ Products $(3$ percent $)$ treatments should have the same effect on 
expectations. Figure 5, panels E and F, show the distribution of expectations under these two treatment arms (see the online Appendix for the rest of treatment arms). We can confidently reject the null hypothesis of rational learning: even though these individuals have the latest inflation statistics readily available to them, they assign a significant weight on much less reliable information on supermarket prices.

Column 2 of Table 1, panel A, shows the estimates of learning rates for the treatment arm Statistics (1.5 percent) + Products. When both statistics and supermarket prices are shown, the $\alpha$ coefficient for the supermarket prices is 0.449 ( $p$-value $<0.01)$, even higher than the $\alpha$ of $0.283(p$-value $<0.01)$ for the statistics (the difference is statistically significant at the 1 percent level). These results suggest that, whenever the two signals disagree with each other, individuals are more willing to incorporate signals closer to their everyday experience, such as a list of price changes for specific products, than signals derived from statistics.

The behavioral framework for thinking about subjective probabilities provides plausible explanations for this finding. A first interpretation has to do with the under-appreciation of the effects of sample sizes on the likelihood of different proportions of a sample (Kahneman and Tversky 1972), also known as nonbelief in the law of large numbers. For instance, Benjamin, Moore, and Rabin (2013) show that averages estimated with sample sizes of 10 and 1,000 are perceived as equally precisely estimated. This could explain why individuals assign as much weight to the supermarket prices (based on fewer than 10 price changes) as they do to inflation statistics (based on thousands of price changes). A second interpretation relies on the concept of the availability heuristic, according to which individuals give more weight to information that is easier to recall. For instance, individuals incorrectly report that there are more words that start with the letter " $k$ " than words with " $k$ " as the third letter, presumably because it takes a more concentrated effort to think of any words in which " $k$ " is the third letter (Tversky and Kahneman 1973). According to the availability heuristic, prices of products are more familiar and easier to recall than inflation statistics, which explains why individuals put so much weight on this information. Last, an alternative interpretation may be that, even in a developed country like the United States, some individuals distrust official statistics (see, Cavallo, Cruces, and Perez-Truglia 2016), or they may fail to comprehend how representative they are.

This evidence suggests that individuals use their own memories of price changes when forming inflation expectations. For example, Bruine de Bruin, van der Klaauw, and Topa (2011) present survey evidence that, when asked about inflation, a majority of individuals report that they try to recall prices of specific products. At the end of our surveys, we also asked individuals about the information they tried to recall. In the control group of our US experiment sample, 64.4 percent of subjects reported trying to recall the prices of specific products, which was twice as much as those trying to recall inflation statistics. In Argentina, even though accurate inflation statistics are widely covered by the media, 74.9 percent of respondents reported trying to recall prices of specific products when asked about past inflation.

We tested more directly the hypothesis that individuals use their price memories in forming inflation expectations. Furthermore, we assessed how misleading the use 
of price memories may be, which depends on the accuracy of these memories. These additional hypotheses required more detailed information about the consumer experience of the individuals, which is difficult to collect in an online survey. To explore these hypotheses further, we conducted an "offline" survey experiment with supermarket customers, which is presented and discussed in Section III.

\section{Spurious Learning Test}

In this section, we measure the extent to which the learning induced by our experimental setup is spurious. To illustrate this concern, we included a treatment arm in which, with the excuse of a numerical literacy question, respondents were provided information on the current and past prices of a fictitious product, with an implied price change of about 10 percent. Under the hypothesis of spurious learning, individuals being asked to "eyeball" this 10 percent price change would be more likely to anchor their inflation expectations around 10 percent. Figure 5, panel B, compares the distribution of inflation expectations between the control group and the Hypothetical treatment group in the US sample. Consistent with the hypothesis of spurious learning, the fictitious signal of a 10 percent price change increased the density around the 10 percent range of inflation expectations (the ES test indicates a statistically significant difference in the distribution of inflation expectations between these two groups). For instance, respondents in the Hypothetical treatment arm were 4.8 percentage points more likely than those in the control group to state that their inflation expectations for the following year were exactly 10 percent $(p$-value $<0.01)$.

Column 1 of Table 1, panel A, reports the implied learning rate from the Hypothetical treatment. The corresponding $\alpha$ is 0.232 and statistically significant at the 1 percent level. Though significant, this rate is economically less significant when compared to the learning rates for the other informational treatments. The effect of this treatment may be attributable to unconscious numerical anchoring. Alternatively, this evidence may reveal that some individuals are so uninformed about inflation that they are even willing to use inflation figures from a hypothetical exercise as a benchmark. In any case, the evidence suggests the presence of some degree of spurious learning.

It is important to note that we compared individuals who were shown the financial literacy questions (regardless of what they answered) versus individuals who were not asked that question. Because we randomized who sees the financial literacy question, this variation is exogenous. Although the correct answer to the financial literacy question was 10 percent, some individuals did not respond correctly (21 percent, to be precise). This led to an underestimation of spurious learning (i.e., if individuals responded some value $\mathrm{X}$ percent different from 10 percent, then we should have observed anchoring of inflation expectations around $\mathrm{X}$ percent rather than around 10 percent).23

\footnotetext{
${ }^{23}$ We could see whether, relative to the control group, individuals responding $\mathrm{X}$ percent to the financial literacy question tend to anchor their inflation expectations around $\mathrm{X}$ percent for each possible value of $X=\{1 \%, 5 \%, 10 \%, 100 \%\}$. However, we refrain from making this comparison, because the responses to the financial literacy questions were not randomized and thus are most likely endogenous.
} 
The first methodology to filter out spurious learning consists of estimating the learning model using inflation expectations in the follow-up survey. We used data on a subsample of 1,073 subjects who were reinterviewed two months after the original online experiment. This subsample was asked again about their inflation expectations, but they were not subjected to any type of new informational treatment or reminded of previous informational treatments. Column 3 of Table 1, panel A, presents the results of the basic regression with inflation expectations in the original survey as the dependent variable, but only for the subsample of those who later participated in our follow-up survey in the United States. The $\beta$ and $\alpha$ coefficients are similar to those presented in column 1 for the full sample.

Column 4 of Table 1, panel A, presents the regression for the same follow-up subsample but with inflation expectations as reported in the follow-up survey as the dependent variable. The $\beta$ coefficient is now substantially lower, falling from 0.814 in column 3 to 0.438 in column 4 . This result is consistent with our learning model, because the $\beta$ coefficient is the product of two terms: the pass-through from perceptions to expectations and the pass-through from inflation perceptions in the original survey to inflation perceptions in the follow-up survey. The $\alpha$ coefficients of 0.360 for the Statistics treatment and of 0.336 for the Products treatment are both statistically significant (at the 1 percent and 5 percent levels, respectively). However, they are about half as large as the coefficients of 0.799 and 0.697 from column 3 . These estimates suggest that between 45 percent (i.e., $\frac{0.360}{0.799}$ ) and 48 percent (i.e., $\frac{0.336}{0.697}$ ) of the effect of the information provided can be attributed to genuine, rather than spurious, learning. Notably, the $\alpha$ coefficient for the Hypothetical treatment in the follow-up results in column 4 is close to zero and statistically insignificant, in contrast to the small but positive and significant effect in column 3. This evidence suggests that our methodology may have successfully filtered out the spurious learning.

Columns 3 and 4 of Table 1, panel B, reproduce the above results but for the Argentine sample instead of the US sample. A subsample of 1,320 of the subjects from the Argentine opinion poll sample were reinterviewed four months after the original survey. ${ }^{24}$ As in the case of the United States, the $\beta$ coefficient is lower for the follow-up regression, falling from 0.963 in column 3 to 0.754 in column 4.25 The $\alpha$ coefficient of 0.208 is statistically significant, but only half as large as the coefficient in column 3 , indicating that about 45.6 percent (i.e., $\frac{0.208}{0.456}$ ) of the effect of the information provided can be attributed to genuine, rather than spurious, learning. This reinforces the findings of the US online experiment, which showed a proportion of genuine learning of about 45 percent in the context of a similar follow-up survey.

The second methodology for filtering out spurious learning consists of measuring learning rates based on the indirect effect of the information provided on the expected

\footnotetext{
${ }^{24}$ There was no significant difference in the probability of participating in the follow-up sample between the treatment and the control groups.

${ }^{25}$ Comparing the $\beta$ coefficient between the follow-up and the original samples provides a measure of the persistence of beliefs. This evidence suggests that expectations are more persistent in Argentina than in the United States; that is, the $\beta$ for the follow-up survey is only 53.8 percent of the same coefficient in the original survey in the United States (0.438 and 0.814, Table 1), while in Argentina the corresponding proportion is 78.2 percent $(0.754$ and 0.963 , Table 1$)$.
} 
nominal interest rate. In the US sample, we report results from this exercise in column 5 of Table 1, where the dependent variable is an individual's expectation for the nominal interest rates for the following 12 months. The $\beta$ coefficient indicates that for each additional percentage point in expected inflation, on average, subjects believed that the nominal interest rate would be about 0.3 percentage points higher. This is consistent with Behrend (1977), who presents evidence that individuals have a significant amount of useful understanding of the link between inflation and other economic outcomes, such as the nominal exchange rate. The estimated $\alpha$ are 0.314 for the Statistics treatment (borderline insignificant at the 10 percent level) and 0.499 for the Products treatment (significant at the 1 percent level). When these parameters are compared to those presented in column 1, they suggest that between 37.5 percent (i.e., $\frac{0.314}{0.838}$ ) and 72.5 percent (i.e., $\frac{0.499}{0.689}$ ) of the learning is genuine. The average between these two figures, 55 percent, is close to the corresponding share of genuine learning inferred from the follow-up survey (46.6 percent). That is, both of these methodologies provide similar estimates of the degree of spurious learning. The results in column 5 indicate that the Hypothetical treatment arm did not have a significant effect on individuals' expected interest rates. This, again, can be interpreted as evidence that this methodology effectively weeds out spurious learning.

Column 5 of Table 1, panel B, reproduces the specification from column 5 of Table 1, panel A, but for Argentina instead of the United States. In this case, the $\alpha$ coefficient of 0.468 is close to the baseline value from column 2 of Table 1, panel B (0.494). This estimate suggests that 95 percent (i.e., $\left.\frac{0.468}{0.494}\right)$ of learning is genuine. However, this estimate is less precisely estimated, and we cannot reject the null hypothesis that only 50 percent of the learning is genuine.

The results for the nominal interest rate also support our findings in a more general way. Our survey questions always refer to inflation expectations in the sense of changes in the average general price level. However, it may be argued that individuals may mistakenly respond as if we asked about their own idiosyncratic inflation (i.e., the price change of their own consumption basket). 20 The results described in this paragraph show that this cannot be the case: changes in inflation expectations affect expectations about nominal variables, like the interest rate (and the exchange rate in the Argentine case, as discussed in the online Appendix), which should not be affected if individuals consider their own idiosyncratic experiences.

In sum, despite a significant level of spurious learning, about half of it is still genuine. More important, once we account for spurious learning, the main results still hold (e.g., it is still true that the learning rate in Argentina is substantially lower than that in the United States).

Additionally, to help establish the validity of the estimation of the learning rates, we test some auxiliary predictions of the Bayesian model. One prediction yielded by this model is that providing relevant information will increase the accuracy of the posterior belief. We test this hypothesis with our data, using the respondents' self-reported confidence in their own inflation expectations on a scale from "very

\footnotetext{
${ }^{26}$ Indeed, Armantier et al. (2016) find that information about food prices causes consumers to update expectations more for their own basket inflation rate but less for their rate of inflation.
} 
sure" to "very unsure." Higher values of this confidence variable indicate higher confidence, and this variable is standardized to have a standard deviation of 1 . In the United States, relative to the control group, the Statistics (1.5 percent) treatment increases confidence by 0.324 ( $p$-value $<0.01)$, the Products treatments increases confidence by 0.226 ( $p$-value $<0.01)$, the combined Products + Statistics $(1.5$ percent) increases confidence by 0.368 , and the Hypothetical treatment increases confidence by a nonsignificant 0.032 ( $p$-value of 0.54 ). This pattern of results indicates a larger increase in confidence as we provide more factual information to our subjects. There is no change when we provide only the (nonfactual) Hypothetical treatment. Similarly, in Argentina's sample I, relative to the control group, the Statistics (24 percent) treatment increased standardized confidence by 0.197 ( $p$-value of 0.07 ), and the combined Products treatments increased confidence by 0.152 ( $p$-value of 0.09 ); whereas for sample II, the combined Products treatments increased confidence by 0.360 ( $p$-value $<0.01$ ) compared to that of the control group.

The Bayesian model also predicts that all signals from the same source should be equally informative to respondents, regardless of their value. In terms of the sub-treatments, Figure 6, panel AII, compares the impact of each level of price changes on the confidence in inflation expectations for the Products treatment arm in the United States. The evidence is consistent with this prediction, although we cannot reject the hypothesis that all positive signals ( 1 percent -7 percent) have the same effect on confidence ( $p$-value of 0.77 ), and we cannot reject the hypothesis that all non-positive signals ( -2 percent, -1 percent, and 0 percent) have the same effect on confidence ( $p$-value of 0.83$)$. We can, however, reject the hypothesis that positive and negative signals have the same effect on confidence $(p$-value $<0.01)$, which suggests that individuals might be less prone to incorporate information about price decreases than about price increases. Figure 6, panel BII, reproduces the analysis of Figure 6, panel AII, for the Argentine experiment (sample II). The results suggest that, consistent with the Bayesian model, all these different signals led to the same gain in confidence about the posterior belief: we cannot reject the null hypothesis that all signals have the same effect on posterior confidence ( $p$-value of 0.73).

Another prediction of the Bayesian model is that the strength of the reaction to new information should depend on the strength of the prior. We can test this hypothesis using the subjective measure of confidence in the prior belief. Figure 7 , panel A, presents the value of the $\alpha$ coefficient corresponding to the reaction to the Products treatment, split by individuals with "High Confidence" and with "Low Confidence" in their stated inflation perceptions (United States corresponds to panel A and Argentina to panel B). The "High Confidence" group corresponds to those who answered "Sure" or "Very Sure" when asked about their confidence on their inflation perceptions, and the "Low Confidence" group corresponds to those who replied "Somewhat Sure," "Unsure," or "Very Unsure." As predicted, in both countries the learning rates as captured by the $\alpha$ coefficient are higher (i.e., individuals react more to the new information) for those with lower levels of confidence in their prior beliefs about inflation. In the US sample, the learning rate is 0.75 for "Low Confidence" and 0.58 for "High Confidence," with a statistically significant difference ( $p$-value 0.03). In Argentina, the learning rate is 0.62 for "Low Confidence" 
Panel A. United States

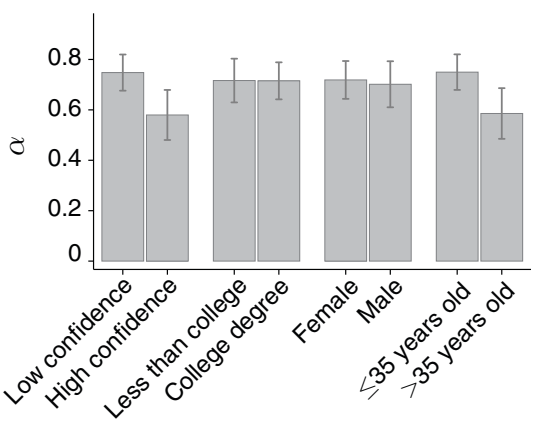

Panel B. Argentina

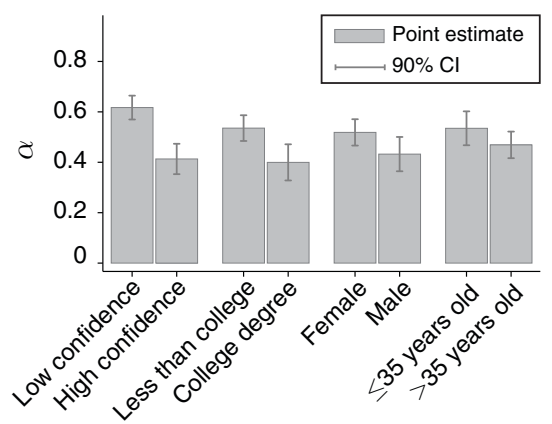

Figure 7. Heterogeneity in Learning Rates, US and ARgentina OnLine EXPeriments

Notes: The total number of observations in panel A (US online experiment) is 1,552 (789 from the control group and 763 from the 10 variations of the Products treatment). The total number of observations in panel B (Argentina online sample II) is 3,653 (567 from the control group and 3,086 from the 19 variations of the Products treatment). For both panels, the "High Confidence" group corresponds to those who answered "sure" or "very sure" when asked about their confidence on their inflation perceptions, and the "Low Confidence" group corresponds to those who replied "somewhat sure," "unsure," or "very unsure." The bars represent the coefficient $\alpha$ obtained from the regression described by equation (6) for each of the pairs of mutually exclusive groups. The confidence intervals are computed with robust standard errors.

and 0.41 for "High Confidence," also with a statistically significant difference between the two coefficients $(p$-value $<0.01)$.

As a final robustness check, we measured the heterogeneity in learning rates with respect to individual demographic characteristics and compared those results with the findings reported in other papers about the heterogeneity of biases in expected inflation. Figure 7 presents this heterogeneity by computing the learning rates for different subgroups of the population (panel A for the United States and panel B for Argentina). Overall, the direction of the effects is identical across the two countries, with learning rates being lower for male, educated, and older individuals, although the differences tend to be more pronounced in Argentina than in the United States in terms of economic and statistical significance. 27 This heterogeneity in learning rates is consistent with the evidence discussed in existing literature, for example, showing that female, less educated, and younger individuals from the United States tend to be less informed about inflation and have more biased inflation expectations (Bruine de Bruin, van der Klaauw, and Topa 2011; Malmendier and Nagel 2016; and Armantier et al. 2016).

\footnotetext{
${ }^{27}$ Females have larger learning rates than males: 0.719 for females compared to 0.702 for males in the United States ( $p$-value of the difference $=0.81)$, and 0.519 compared to 0.432 in Argentina ( $p$-value $=0.07)$. Individuals with a college degree sometimes have lower learning rates than individuals without such degree: 0.715 for college graduates compared to 0.716 for nongraduates for the United States ( $p$-value $=0.99$ ), and 0.4 compared to 0.535 for Argentina ( $p$-value $<0.01$ ). Older subjects (those older than 35 years old) have lower learning rates than their younger counterparts: 0.586 for the older compared to 0.750 for the younger for the United States $(p$-value $=0.03)$, and 0.469 compared to 0.535 for $\operatorname{Argentina}(p$-value $=0.16)$.
} 


\section{The Supermarket Experiment}

\section{A. Remaining Hypotheses to Be Tested}

The evidence from the online experiments indicates that, even when inflation statistics are readily available, individuals pay attention to prices of specific products in forming their inflation perceptions and expectations. This is suggestive evidence that individuals use their price memories to form inflation expectations. In this section, we discuss an "offline" survey with supermarket customers designed to strengthen our understanding of this issue.

One remaining hypothesis is that, even though suggestive, these findings do not constitute conclusive evidence that individuals use price memories to form inflation expectations. For example, subjects may have reacted to the price information insofar as they perceived it to be accurate, but they would not trust their own price memories for the same products. Another remaining hypothesis predicts whether the use of price memories leads to significantly biased inflation expectations: the more inaccurate the price memories, the more misleading their use will be.

Addressing these two remaining hypotheses requires data that is difficult to collect in an online survey, because it involves products purchased by subjects, historical prices of those products, individual memories of those historical prices, and individual inflation perceptions and expectations. Moreover, we would need a source of exogenous variation in the price memories of subjects. We designed and conducted a unique consumer intercept survey to meet all of these requirements, and we conducted the survey at the main exit of some supermarkets in Buenos Aires.

\section{B. Subject Pool and Experimental Design}

The consumer intercept survey was carried out in four branches of one of the largest supermarket chains in the city of Buenos Aires. The subject pool consisted of supermarket customers who had just finished shopping. When exiting the supermarket, they were invited to participate in a short survey for an academic study. A total of 1,200 subjects were interviewed for about three to five minutes, yielding 1,140 observations with complete information about relevant outcomes. Using handheld scanners, the interviewers scanned respondents supermarket receipts, which contained product identifiers that could be matched to our online-scrapped price database for the supermarket chain where the study was conducted.

After providing purchase receipts for scanning, respondents were asked 12 questions. Some questions asked about the current and past prices of supermarket products that the individuals just bought. Specifically, respondents were asked to recall the current price and the price from 12 months earlier of two specific products they had just purchased, chosen at random by the interviewer from the receipt. The interviewers selected two additional products from the receipt, read each of their prices out loud, and asked the respondents what they thought the prices of these two products had been 12 months earlier.

These questions had a double purpose: measuring the accuracy of price memories and the effect of price memories on inflation expectations. For the second goal, we 
followed a design similar in spirit to the online experiments. First, we asked about perceptions of the inflation rate over the past year. Next, we asked individuals about the prices of a random set of four products. Last, we asked about expectations for the inflation rate for the following 12 months. This information-retrieval exercise intended to generate random variation in the salience of the individual's own price memories about four specific products randomly chosen from the receipt. In the online experiments, we provided a table with specific, preselected product prices and price changes. This supermarket experiment also consisted of a list of four products at random, although this time they corresponded to products that the individual had just purchased and thus were relevant for them. Most important, instead of providing the historical prices for these four products, we asked respondents to "fill in the table" by using their own price memories. By chance, some of the products we made salient through this procedure corresponded to products with larger or smaller actual price changes, or with larger or smaller remembered price changes. This design allowed us to test whether making these products salient had any effect on subsequent individuals' inflation expectations. Unlike in the other informational treatments in our study, subjects did not learn new information. Rather, we made information that they already had salient. 28

\section{Accuracy of Memories about Current and Past Prices}

The goal of this section is to compare the memories about current and past prices to the actual prices. Panel A in Figure 8 presents a scatterplot of prices for the products the respondents had just purchased. The prices that the respondents reported paying (without looking at their receipts) are on the vertical axis, and the prices that they actually paid are on the horizontal axis. The relationship between the two variables seems to be linear, with most observations clustered around the 45 degree line, indicating that individuals' memories of the prices of the products they had just purchased were fairly accurate. Panel B in Figure 8 presents the results of a more taxing exercise for respondents' memories: we present a scatterplot of respondents' reported recollections of the prices of the same goods one year earlier (vertical axis) and of the actual prices one year earlier (horizontal axis), obtained from our database of scrapped prices for the same supermarket chain. The main pattern that emerges indicates that individuals' recalled prices for one year earlier are systematically lower than the actual prices of those products at that time, as indicated in our database. 29 Moreover, the $R^{2}$ of the predictions provided by the individuals about current prices is 0.81 . Although not a perfect fit, the relationship is very tight. However, the $R^{2}$ drops to just 0.65 when individuals are asked about past prices. A significant part of that drop in predictive power is likely due to the fact that individuals systematically underestimate past prices. Because individuals have relatively

\footnotetext{
${ }^{28}$ As a benchmark, we also included a second informational treatment that was identical to the one used in the online experiments, consisting of showing the actual price histories for six randomly selected products (results reported in the online Appendix).

${ }^{29}$ This underestimation of past prices may be due in part to the fact that individuals may struggle with the operation of projecting percentage changes into the past. See, for example, the discussion about implicit memory in Monroe and Lee (1999).
} 
Panel A. Current prices: Actual versus remembered

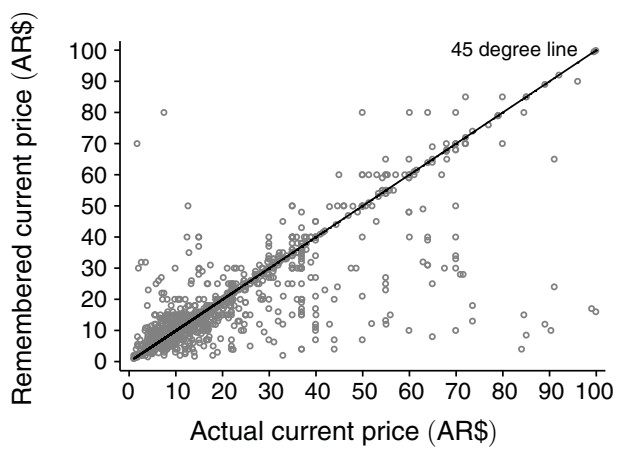

Panel C. Remembered price changes (percent) versus inflation perceptions

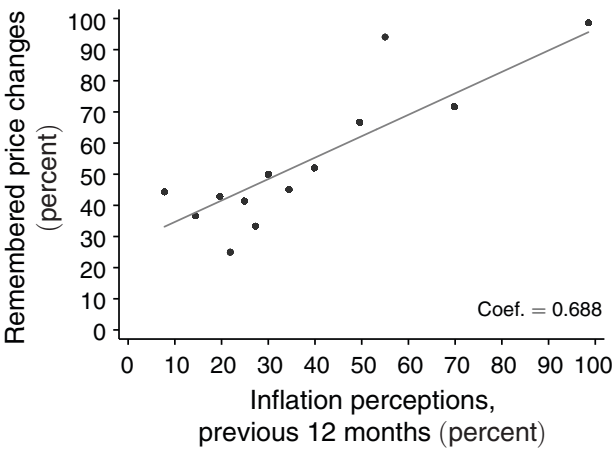

Panel E. Effect of remembered price changes

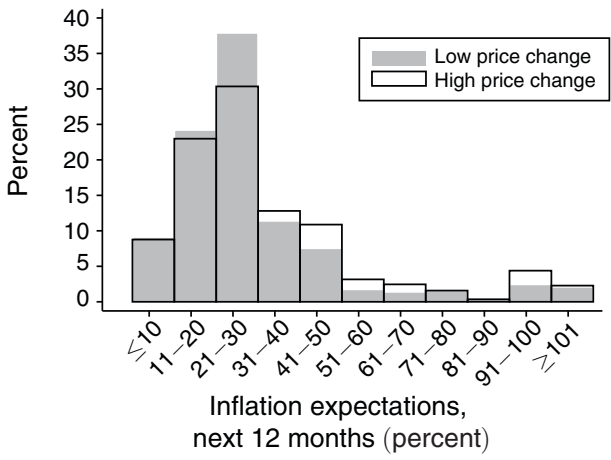

Note: ES test $p$-value: $<0.01$.
Panel B. Past prices: Actual versus remembered

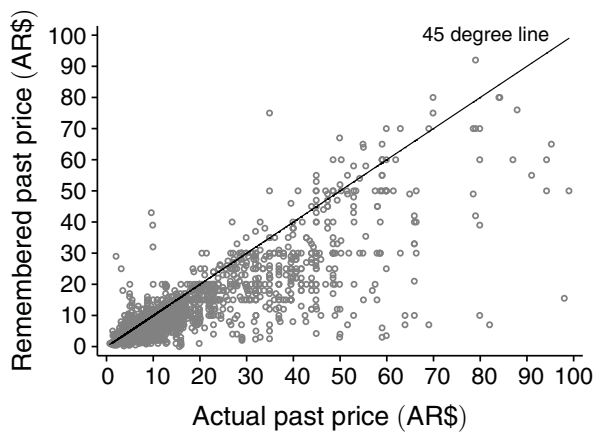

Panel D. Price changes (percent): Actual versus remembered

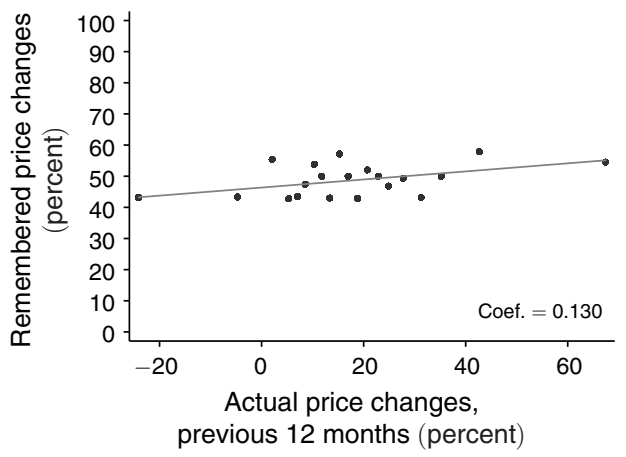

Panel F. Effect of actual price changes

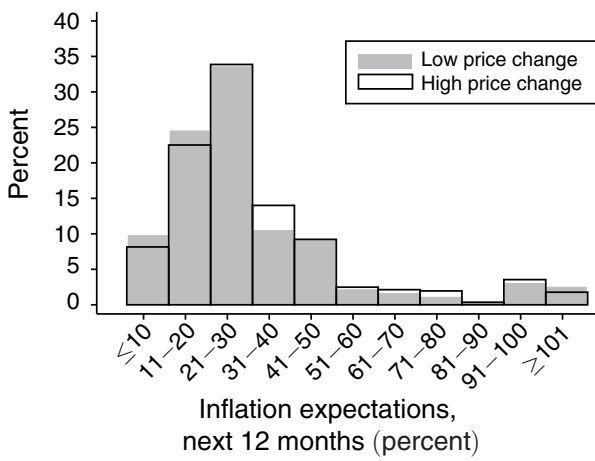

Note: ES test $p$-value: 0.30 .

\section{Figure 8. Results From the SuPERMarket EXPERIMENT}

Notes: The data in this figure corresponds to the Argentina Supermarket Experiment. The total number of observations is 1,140 for panels A, B, C, D, and E, and 1,127 for panel F. Panels C and D represent binned scatter plots, where the number of observations is almost identical across bins. The annual price changes in panels $\mathrm{C}$ and $\mathrm{D}$ are implicit; they are obtained from the current and past prices in Argentine pesos (AR\$) reported by the respondents. In panel E, the High/Low Price Change corresponds to individuals above/below the median of remembered price changes, after controlling for inflation perceptions. In panel F, the High/Low Price Change corresponds to individuals above/below the median actual price changes, after controlling for inflation perceptions. ES is the Epps-Singleton characteristic function test of equality of two distributions. 
unbiased memories of current prices but tend to underestimate past prices, they often overestimate price changes.

This evidence is consistent with literature in psychology documenting large biases in remembered prices (e.g., Bates and Gabor 1986, Kemp 1987, and Monroe and Lee 1999). Unlike the existing literature, however, our evidence shows that these biases are substantial even in a context of high inflation and in a natural environment for consumers, such as the products and brands that the consumers actually buy at the supermarket.

Although price changes are overestimated on average, there may be a correlation between remembered price changes and actual price changes. For instance, individuals might be mistakenly reporting prices from twenty months earlier rather than from 12 months earlier. Panel D in Figure 8 presents a comparison of the remembered price changes and the actual price changes observed in our database of supermarket prices. There is a weak correlation between the two: for each percentage point increase in the actual price change, the remembered price change increases by only 0.13 percentage points

In the online Appendix, we show that individuals are similarly inaccurate when asked about the changes in bundles of products instead of specific products. However, individuals may follow the evolution of prices for a different set of products (e.g., a handful of "favorite" goods), and their memories for these products may be more accurate. With this caveat in mind, in the online Appendix we show that even with perfectly accurate recollections, if the number of products that an individual keeps track of is small, that can generate substantial excess dispersion in inflation expectations, enough to explain the dispersion of inflation expectations observed in the data.

Finally, noisy memories about past prices may also arise mechanically in the absence of behavioral biases. For instance, in a model with information frictions where individuals can carry only a limited amount of information, individuals may use current prices and inflation perceptions to "backcast" past prices (Woodford 2009). However, this mechanism does not fully explain our data. For instance, a regression of remembered price changes on the inflation perceptions rate yields an $R^{2}$ of 0.057 , which suggests that the vast majority of the variation in remembered price changes cannot be explained by "backcasting."

\section{Evidence on the Use of Actual and Remembered Price Changes in the Formation of Inflation Expectations}

Panel E in Figure 8 presents evidence on the effect of remembered price changes on inflation expectations. It presents a comparison of the distribution of inflation expectations when, conditional on the individual's inflation perceptions, we made salient products that the individual remembered to have larger and smaller price

\footnotetext{
${ }^{30}$ As a benchmark, panel $\mathrm{C}$ in Figure 8 presents respondents' perceptions of aggregate inflation over the previous 12 months and the implicit average percentage price change of the products for which we requested this information. As expected, the correlation is positive and significant (i.e., individuals who believed inflation was high also believed that, on average, prices of specific products increased more). For each percentage point increase in perceptions of past inflation, the remembered price change increases by about 0.69 percentage points.
} 
changes.3 The results from this exercise indicate that making salient those products with larger remembered price changes generates higher inflation expectations. The distributions differ significantly, as suggested by the ES test, and inflation expectations are 32.77 percent for the group of products with smaller remembered price changes compared to 37.38 percent for the group of products with larger remembered price changes (the difference is significant at the 1 percent level). This finding suggests that individuals use their memories as consumers when forming their inflation expectations.

As previously established, these memories are highly inaccurate, so this may generate substantial biases in expectations. To show this more directly, Panel F in Figure 8 presents a comparison of the distribution of inflation expectations between groups of individuals for which we randomly made salient those products whose actual price changes (rather than their price changes as remembered by the respondents) were larger, following the same methodology used in panel $\mathrm{E}$ for remembered prices. The comparison of the two distributions indicates that making salient those products with actual larger price changes did not result in higher inflation expectations. Although the $p$-value of the ES test suggests that the two distributions differ significantly, the differences are economically small. For example, inflation expectations are 33.44 percent for the smaller actual price changes group, compared to 34.10 percent for the larger actual price changes group. The difference is not statistically significant at standard levels. In other words, it is the remembered price changes and not the actual price changes that mattered for the formation of our subjects' inflation expectations.

The use of price memories as inputs for the formation of inflation expectations tends to induce large errors in beliefs and may cause significant dispersion in expectations. This evidence is consistent with the fact that, although their price memories were actually strongly biased, subjects were largely unaware of these biases. When asked how confident they were, only 9.81 percent of subjects reported to be either "unsure" or "very unsure" about their answers to the questions about prices of specific products. 33

\section{Conclusions}

We presented evidence from a series of survey experiments in which we randomly assigned respondents to treatments that provided different information

\footnotetext{
${ }^{31}$ Specifically, we computed the remembered price change as the average of the price changes of the four randomly selected products that each respondent was asked to state. We then controlled for each individual's inflation perceptions by subtracting the variation in the average remembered price change that can be explained by inflation perceptions, and we divided those residuals into two extreme groups: the top half (i.e., large price changes) and the bottom half (i.e., small price changes).

${ }^{32}$ In this case, unlike the other informational treatments, we did not randomize the recalled price changes directly, but randomized instead the salience of the recalled price changes for a group of products. As a result, estimating the weight assigned to this information (the $\alpha$ coefficient) with our learning regression would not yield the same interpretation in terms of rate of learning, as in the information provision treatments in the online experiments. The online Appendix presents a regression for the corresponding rate of learning, although these results should be interpreted with this caveat in mind.

${ }^{33}$ In comparison, only 9.72 percent reported "unsure" or "very unsure" as responses to the question about the inflation rate over the past 12 months.
} 
related to inflation, such as inflation statistics or price changes for specific products. We used that exogenous variation to estimate the rates of learning from different sources of information. We document two main findings. First, consistent with the rational inattention model, individuals in low inflation contexts have significantly weaker priors about the inflation rate compared to those in high inflation contexts. Second, we found that rational inattention is not the only significant source of information frictions: even when information about inflation statistics is made readily available to them, individuals still place significant weight on less accurate sources of information, such as their own memories of supermarket product prices.

Our findings have several implications for macroeconomic models and policymaking. How households form inflation expectations is an important consideration for central banks insofar as, by anchoring expectations, the policies of monetary authorities attempt to influence decisions that households make about consumption and investment. It is important, then, to incorporate realistic informational frictions in models of household expectations and monetary policy (e.g., Coibion and Gorodnichenko 2015). From a more practical perspective, our findings imply that central banks could influence inflation expectations by disseminating information on individual product prices and communicating how objective, accurate, and representative inflation statistics are.

Our findings also contribute to the discussion on the potential usefulness of survey data on inflation expectations. Some researchers attribute the biases in household inflation expectations to the inherent limitations of self-reported data (Manski 2004), which implies that survey data on household expectations are not useful. 0 Other authors argue that the failure to incorporate public information is a natural outcome of rational inattention (Mankiw, Reis, and Wolfers 2004). This argument implies that survey data on expectations have limited value, because inaccurate expectations merely reveal that the respondents do not care about inflation. Our evidence suggests that individuals report biased beliefs on inflation partly because they use private sources of information (e.g., price memories), even when inflation statistics are readily available. This finding implies that some of the observed heterogeneity in reported inflation expectations reflects actual heterogeneity in deep beliefs rather than measurement error or rational inattention.

\footnotetext{
${ }^{34}$ Of course, the limitations with subjective reports must explain at least part of the dispersion in expectations. For example, Armantier et al. (2011) shows that even though individuals' inflation expectations are correlated to their actual behavior in a financially incentivized investment experiment where future inflation affects payoffs, there are substantial discrepancies correlated to numeric and financial literacy.

${ }^{35}$ Consistent with this interpretation, our survey data reveal that even individuals with biased inflation expectations report significant confidence about their stated expectations. For individuals in the control group in the United States, the average levels of confidence about perceptions of past inflation of 1 percent, 2 percent, and 3 percent (i.e., closest to the average of statistics, 1.5 percent) are 2.6 for past inflation and 2.69 for inflation expectations (on a scale of 1 to 5). The figures for confidence are 2.95 and 2.85 , respectively, for those whose stated perceptions of past inflation were -4 percent or lower or 7 percent or higher.
} 


\section{REFERENCES}

Armantier, Olivier, Wändi Bruine de Bruin, Simon Potter, Giorgio Topa, Wilbert van der Klaauw, and Basit Zafar. 2013. "Measuring Inflation Expectations." Annual Review of Economics 5: 273-301.

Armantier, Olivier, Wändi Bruine de Bruin, Giorgio Topa, Wilbert van der Klaauw, and Basit Zafar. 2011. "Inflation Expectations and Behavior: Do Survey Respondents Act on Their Beliefs?" Federal Reserve Bank of New York Staff Report 509.

-Armantier, Olivier, Scott Nelson, Giorgio Topa, Wilbert van der Klaauw, and Basit Zafar. 2016. "The Price Is Right: Updating Inflation Expectations in a Randomized Price Information Experiment." Review of Economics and Statistics 98 (3): 503-23.

Atkeson, Andrew, and Lee E. Ohanian. 2001. "Are Phillips Curves Useful for Forecasting Inflation?" Federal Reserve Bank of Minneapolis Quarterly Review 25 (1): 2-11.

- Bachmann, Rüdiger, Tim O. Berg, and Eric R. Sims. 2015. "Inflation Expectations and Readiness to Spend: Cross-Sectional Evidence." American Economic Journal: Economic Policy 7 (1): 1-35.

Badarinza, Christian, and Marco Buchmann. 2009. "Inflation Perceptions and Expectations in the Euro Area: The Role of News.” European Central Bank Working Paper 1088.

- Barr, David G., and John Y. Campbell. 1997. "Inflation, real interest rates, and the bond market: A study of UK nominal and index-linked government bond prices." Journal of Monetary Economics 39 (3): 361-83.

- Bates, John M., and André Gabor. 1986. "Price perception in creeping inflation: Report on an enquiry." Journal of Economic Psychology 7 (3): 291-314.

- Behrend, Hilde. 1977. "Research into inflation and conceptions of earnings." Journal of Occupational and Organizational Psychology 50 (3): 169-76.

Benjamin, Daniel, Don Moore, and Matthew Rabin. 2013. "Misconceptions of Chance: Evidence from an Integrated Experiment." http://scholar.harvard.edu/files/rabin/files/misconceptions.pdf.

Bernanke, Ben S. 2007. "Inflation Expectations and Inflation Forecasting." Speech, Monetary Economics Workshop of the National Bureau of Economic Research Summer Institute, Cambridge, MA, July 10.

Blanchflower, David G., and Conall MacCoille. 2009. "The Formation of Inflation Expectations: An Empirical Analysis for the UK." National Bureau of Economic Research (NBER) Working Paper 15388.

- Bruine de Bruin, Wändi, Wilbert van der Klaauw, and Giorgio Topa. 2011. "Expectations of inflation: The biasing effect of thoughts about specific prices." Journal of Economic Psychology 32 (5): 834-45.

Burke, Mary A., and Michael Manz. 2011. "Economic Literacy and Inflation Expectations: Evidence from a Laboratory Experiment.” Federal Reserve Bank of Boston Public Policy Discussion Paper $11-8$.

-Carrillo, Paul E., and M. Shahe Emran. 2012. "Public Information and Inflation Expectations: Microeconometric Evidence from a Natural Experiment." Review of Economics and Statistics 94 (4): 860-77.

Carroll, Christopher D. 2003. "Macroeconomic Expectations of Households and Professional Forecasters." Quarterly Journal of Economics 118 (1): 269-98.

Cavallo, Alberto. 2013. "Online and official price indexes: Measuring Argentina's inflation." Journal of Monetary Economics 60 (2): 152-65.

- Cavallo, Alberto, Guillermo Cruces, and Ricardo Perez-Truglia. 2016. "Learning from Potentially Biased Statistics." Brookings Papers on Economic Activity 46 (1): 59-108.

Cavallo, Alberto, Guillermo Cruces, and Ricardo Perez-Truglia. 2017. "Inflation Expectations, Learning, and Supermarket Prices: Evidence from Survey Experiments: Dataset." American Economic Journal: Macroeconomics. https://doi.org/10.1257/mac.20150147.

- Coibion, Olivier, and Yuriy Gorodnichenko. 2012. "What Can Survey Forecasts Tell Us about Information Rigidities?" Journal of Political Economy 120 (1): 116-59.

-Coibion, Olivier, and Yuriy Gorodnichenko. 2015. "Is the Phillips Curve Alive and Well after All? Inflation Expectations and the Missing Disinflation." American Economic Journal: Macroeconomics 7 (1): 197-232.

Coibion, Olivier, Yuriy Gorodnichenko, and Saten Kumar. 2015. "How Do Firms Form Their Expectations? New Survey Evidence." National Bureau of Economic Research (NBER) Working Paper 21092.

-Crump, Matthew J. C., John V. McDonnell, and Todd M. Gureckis. 2013. "Evaluating Amazon's Mechanical Turk as a Tool for Experimental Behavioral Research.” PLoS ONE 8 (3): e57410. 
Demery, David, and Nigel W. Duck. 2007. "The theory of rational expectations and the interpretation of macroeconomic data." Journal of Macroeconomics 29 (1): 1-18.

Dräger, Lena. 2011. "Inflation Perceptions and Expectations in Sweden-Are Media Reports the 'Missing Link'?" KOF Swiss Economic Institute Working Paper 11-273.

-Gennaioli, Nicola, and Andrei Shleifer. 2010. "What Comes to Mind." Quarterly Journal of Economics 125 (4): 1399-1433.

-Goerg, Sebastian J., and Johannes Kaiser. 2009. "Nonparametric testing of distributions-The Epps-Singleton two-sample test using the empirical characteristic function." Stata Journal 9 (3): 454-65.

Goffman, Erving. 1963. Stigma: Notes on the Management of Spoiled Identity. Englewood Cliffs, NJ: Prentice-Hall.

Hellwig, Christian. 2005. "Heterogeneous Information and the Benefits of Public Information Disclosures." University of California Los Angeles (UCLA) Economics Online Paper 283.

Jonung, Lars. 1981. "Perceived and Expected Rates of Inflation in Sweden." American Economic Review 71 (5): 961-68.

Kahneman, Daniel, and Amos Tversky. 1972. "Subjective probability: A judgment of representativeness." Cognitive Psychology 3 (3): 430-54.

Kemp, Simon. 1987. "Estimation of past prices." Journal of Economic Psychology 8 (2): 181-89.

Lamla, Michael J., and Sarah M. Lein. 2008. "The Role of Media for Consumers' Inflation Expectation Formation.” KOF Swiss Economic Institute Working Paper 201.

-Lucas, Robert E., Jr. 1972. "Expectations and the neutrality of money." Journal of Economic Theory 4 (2): 103-24.

-Madeira, Carlos, and Basit Zafar. 2015. "Heterogeneous Inflation Expectations and Learning." Journal of Money, Credit and Banking 47 (5): 867-96.

-Malmendier, Ulrike, and Stefan Nagel. 2016. "Learning from Inflation Experiences." Quarterly Journal of Economics 131 (1): 53-87.

-Mankiw, N. Gregory, and Ricardo Reis. 2002. "Sticky Information versus Sticky Prices: A Proposal to Replace the New Keynesian Phillips Curve.” Quarterly Journal of Economics 117 (4): 1295-1328.

Mankiw, N. Gregory, Ricardo Reis, and Justin Wolfers. 2004. "Disagreement about Inflation Expectations." In NBER Macroeconomics Annual 2003, Vol. 18, edited by Mark Gertler and Kenneth Rogoff, 209-70. Cambridge: MIT Press.

-Manski, Charles F. 2004. "Measuring Expectations." Econometrica 72 (5): 1329-76.

Monroe, Kent B., and Angela Y. Lee. 1999. "Remembering versus knowing: Issues in buyers' processing of price information." Journal of the Academy of Marketing Science 27 (2): 207-25.

- Morris, Stephen, and Hyun Song Shin. 2002. "Social Value of Public Information." American Economic Review 92 (5): 1521-34.

-Mullainathan, Sendhil. 2002. "A Memory-Based Model of Bounded Rationality." Quarterly Journal of Economics 117 (3): 735-74.

Phelps, Edmund S. 1969. “The New Microeconomics in Inflation and Employment Theory.” American Economic Review 59 (2): 147-60.

- Ranyard, Rob, Fabio Del Missier, Nicolao Bonini, Darren Duxbury, and Barbara Summers. 2008. "Perceptions and expectations of price changes and inflation: A review and conceptual framework." Journal of Economic Psychology 29 (4): 378-400.

- Roos, Michael W. M., and Ulrich Schmidt. 2012. "The Importance of Time-Series Extrapolation for Macroeconomic Expectations." German Economic Review 13 (2): 196-210.

Rosenthal, Robert. 1966. Experimenter effects in behavioral research. New York: AppletonCentury-Crofts.

Sargent, Thomas J. 1993. Bounded Rationality in Macroeconomics. Oxford: Oxford University Press.

Sims, Christopher. 2005. "Rational inattention: A research agenda." Deutsche Bundesbank Discussion Paper 34/2005.

Tversky, Amos, and Daniel Kahneman. 1973. "Availability: A heuristic for judging frequency and probability." Cognitive Psychology 5 (2): 207-32.

-Tversky, Amos, and Daniel Kahneman. 1974. "Judgment under Uncertainty: Heuristics and Biases." Science 185 (4157): 1124-31.

Veldkamp, Laura L. 2011. Information Choice in Macroeconomics and Finance. Princeton: Princeton University Press.

-Woodford, Michael. 2009. "Information-constrained state-dependent pricing." Journal of Monetary Economics 56 (Supplement): S100-124.

Zizzo, Daniel John. 2010. "Experimenter demand effects in economic experiments." Experimental Economics 13 (1): 75-98. 


\section{This article has been cited by:}

1. THERESA KUCHLER, BASIT ZAFAR. 2019. Personal Experiences and Expectations about Aggregate Outcomes. The Journal of Finance 74:5, 2491-2542. [Crossref]

2. Olga Goldfayn-Frank, Johannes Wohlfart. 2019. Expectation formation in a new environment: Evidence from the German reunification. Journal of Monetary Economics . [Crossref]

3. Daniel Martin, Edwin Mu\&ntilde;oz-Rodriguez. 2019. Misperceiving Mechanisms: Imperfect Perception and the Failure to Recognize Dominant Strategies. SSRN Electronic Journal . [Crossref]

4. Francesco D'Acunto, Daniel Hoang, Maritta Paloviita, Michael Weber. 2019. IQ, Expectations, and Choice. SSRN Electronic Journal . [Crossref]

5. Lenard Lieb, Johannes Schuffels. 2019. Inflation Expectations and Consumer Spending: The Role of Household Balance Sheets. SSRN Electronic Journal . [Crossref]

6. Federica Di Giacomo, Cristina Angelico. 2019. Heterogeneity in Inflation Expectations and Personal Experience. SSRN Electronic Journal . [Crossref]

7. Francesco D'Acunto, Daniel Hoang, Michael Weber. 2019. Managing Households' Expectations with Salient Economic Policies. SSRN Electronic Journal . [Crossref]

8. Olivier Coibion, Yuriy Gorodnichenko, Rupal Kamdar. 2018. The Formation of Expectations, Inflation, and the Phillips Curve. Journal of Economic Literature 56:4, 1447-1491. [Abstract] [View PDF article] [PDF with links]

9. Stefano DellaVigna, Devin Pope. 2018. Predicting Experimental Results: Who Knows What?. Journal of Political Economy 126:6, 2410-2456. [Crossref]

10. Olivier Coibion, Yuriy Gorodnichenko, Saten Kumar. 2018. How Do Firms Form Their Expectations? New Survey Evidence. American Economic Review 108:9, 2671-2713. [Abstract] [View PDF article] [PDF with links]

11. Abraham Lioui, Andrea Tarelli. 2018. Money Illusion: A Rationale for the Tips Puzzle. SSRN Electronic Journal . [Crossref]

12. Andreas Fuster, Ricardo Perez-Truglia, Basit Zafar. 2018. Expectations With Endogenous Information Acquisition: An Experimental Investigation. SSRN Electronic Journal . [Crossref]

13. Carola Binder, Christos Makridis. 2018. Stuck in the Seventies: Gas Prices and Macroeconomic Expectations. SSRN Electronic Journal . [Crossref]

14. Tami Kim, Daniel Martin. 2018. Inference about Ratings: How Good Is a Good Rating?. SSRN Electronic Journal . [Crossref]

15. Wändi Bruine de Bruin, Baruch Fischhoff. 2017. Eliciting probabilistic expectations: Collaborations between psychologists and economists. Proceedings of the National Academy of Sciences 114:13, 3297-3304. [Crossref]

16. Marcelo BBrgolo, Guillermo Cruces, Matias Giaccobasso. 2017. Tax Audits as Scarecrows: Evidence from a Large-Scale Field Experiment. SSRN Electronic Journal . [Crossref]

17. Augustin Landier, Yueran Ma, David Thesmar. 2017. New Experimental Evidence on Expectations Formation. SSRN Electronic Journal . [Crossref]

18. Laura Bartiloro, Marco Bottone, Alfonso Rosolia. 2017. What Does the Heterogeneity of the Inflation Expectations of Italian Firms Tell Us?. SSRN Electronic Journal . [Crossref]

19. Carola Conces Binder. 2016. Fed Speak on Main Street: Central Bank Communication and Household Expectations. SSRN Electronic Journal . [Crossref] 